$r_{e}$ ALA

I. Estudios 



\title{
La autonomía local en Alemania a los dos siglos de su nacimiento: su posición jurídico-institucional'
}

\author{
Ricard Gracia Retortillo \\ Profesor ayudante de Derecho Administrativo. Universidad de Barcelona \\ rgracia@ub.edu
}

\begin{abstract}
Resumen
Este artículo analiza la posición jurídico-institucional de los gobiernos locales en la actual República Federal de Alemania. Al hilo de la reciente conmemoración del bicentenario del nacimiento de la autonomía local en Alemania, se actualizan las posiciones doctrinales y jurisprudenciales mayoritarias que configuran hoy el marco constitucional del gobierno local en el Estado federal alemán. Para ello, se estudia el alcance con el que la recientemente modificada Constitución Federal y las de los respectivos Länder garantizan los principios democrático y de autonomía en el nivel local. A su vez, se presta atención a la especial vinculación que, como resultado de la concepción federal del Estado, tienen los gobiernos locales con los Länder, encargados en exclusiva de la configuración legal de su régimen jurídico, de su control administrativo y de su dotación financiera. En conclusión, se pone de relieve como dicho marco federal resulta a la vez límite y fomento para la diversidad normativa a la que se halla sometida la configuración jurídica del gobierno local en la Alemania actual.
\end{abstract}

\section{Local self-government in Germany two centuries after its birth: legal and institutional position}

\begin{abstract}
This article analyzes the institutional and legal position of local governments in the Federal Republic of Germany. In line with the recent commemoration of the bicentennial of the birth of local autonomy in Germany, the article updates doctrinal and jurisprudential positions that make up today the constitutional framework of local government in the German federal State. To this end, the article studies how the recently amended Federal Constitution and the respective Länder's Constitutions guarantee principles of democracy and autonomy at the local level of government. It also pays attention to the special relationship, which, as a result of the state's federal conception, local entities have with the Länder, who are responsible for the exclusive configuration of its legal status, for its administrative control and its funding. In conclusion, the article emphasizes that the federal system is both limit and promotion for the legal diversity, which characterizes the current legal configuration of local government in Germany.
\end{abstract}

Key words

Germany, local autonomy, federalism, democracy, Constitution, municipality, Kreis.

1 Este trabajo se enmarca en el Proyecto de Investigación DER2009-14265-C02-01, del que es investigador principal el Dr. Alfredo Galán Galán. Para su realización, el autor contó con la financiación del Institut d'Estudis Autonòmics de la Generalitat de Catalunya, que le concedió una beca para realizar una estancia de investigación en la Universidad de Konstanz durante los meses de julio a diciembre de 2009, bajo la dirección del profesor Dr. Martin Ibler. 


\section{LA ACTUALIDAD DE LA AUTONOMÍA LOCAL EN ALEMANIA²}

La autonomía local está de actualidad en Alemania. En los últimos años se han conmemorado diversos aniversarios que tienen que ver con lo que unánimemente se considera el punto de partida para la construcción moderna de la autonomía local (kommunale Selbstverwaltung) en dicho Estado: la célebre Ordenanza prusiana de Ciudades (Städteordnung) de 19 de noviembre de 1808. Además del segundo centenario de la aprobación de dicha ordenanza, en 2007 se cumplieron 250 años del nacimiento del barón Karl von Stein, Ministro de Economía y Finanzas en tiempos del reinado de Federico Guillermo III de Prusia, verdadero impulsor de dicha regulación y "alma mater" de la inconclusa reforma político-administrativa del Estado en la que aquella se enmarcó. Las líneas maestras y las bases ideológicas de dicha reforma se contenían fundamentalmente en la llamada "Memoria de Nassau" (Nassauer Denkschrift), cuyo 200 aniversario tuvo lugar también en el mismo año 2007. La conjunción de todas estas celebraciones ha dado pie a múltiples reflexiones doctrinales sobre la construcción teórica actual de la autonomía local, recuperando el debate sobre la vigencia en nuestros días del ideario del propio von Stein, a la vez que se ha visto por las organizaciones asociativas locales como una buena oportunidad para reivindicar el refuerzo de la posición del nivel local en el conjunto del Estado federal. ${ }^{3}$

No obstante, la actualidad del gobierno local en Alemania no se reduce exclusivamente a esta, por otra parte nada desdeñable, perspectiva teórico-dogmática. Contrariamente, en los últimos años, pueden identificarse también una serie de reformas legislativas, a diferentes niveles, que han situado en primera línea el debate político-normativo sobre el gobierno local. Así, por ejemplo, algunos Länder han emprendido una serie de reformas administrativas de carácter funcional y territorial (Funktional- und Gebietsreformen), que tienen por objeto de manera fundamental a los entes locales y especialmente a su nivel supramunicipal. Entre otras medidas, se han propuesto, con éxito diverso, nuevas reordenaciones territoriales del Kreis, agru-

2 En el presente trabajo se utilizan las siguientes abreviaturas, manteniéndose, cuando se ha considerado oportuno para facilitar el acceso a las fuentes originales, su versión en alemán:

BVerfGE: Sentencia del Tribunal Constitucional Federal alemán.

GG: (Grundgesetz): Ley Fundamental de Bonn de 1949 o Constitución federal.

LVerf o Verf (Landesverfassung): Constitución del Land.

En cuanto a las denominaciones de los $L a ̈ n d e r$, se ha utilizado su denominación castellana, para facilitar su identificación por el lector español. No obstante, se utilizan las abreviaturas alemanas: BW (BadenWurtemberg), Bay (Baviera), Bbg (Brandemburgo), Hess (Hesse), MV (Mecklemburgo-Pomerania Occidental), Nds (Baja Sajonia), NW (Renania del Norte-Westfalia), Rh-Pf (Renania-Palatinado), Sachs (Sajonia), S-Ahn (Sajonia-Anhalt), Saarl (Sarre), S-H (Schleswig-Holstein), Thür (Turingia).

3 Entre las recientes reflexiones doctrinales a las que hacemos referencia, Mempel, M. (2007), "Von der Stein-Zeit ins 21. Jahundert - Kommunale Selbstverwaltung in Zeiten des demografischen Wandels", Der Landkreis (12): 607 y ss. Henneke, H-G. y Ritgen, K. (2007), “Aktivierung bürgerschaftlicher Selbst-Verwaltung in Städten, Kreisen und Gemeinden - zur Bedeutung der Lehren des Freiherrn vom Stein für die kommunale Selbstverwaltung der Gegenwart”, Deutsches Verwaltungsblatt, 20: 1253-1266; en respuesta al anterior, Faber, H. (2008), "Erwiderung auf den Beitrag von Henneke und Ritgen zum 250. Geburtstag des Freiherrn vom Stein und zu seiner Bedeutung für die kommunale Selbstverwaltung”, Deutsches Verwaltungsblatt, 7: 437 y ss. 
pación de municipios generalizada en el conjunto de la Federación, con la finalidad de dar paso a entidades de ámbito territorial regional (Regionalkreisbildung), suscitándose relevantes e interesantes debates -incluso en sede jurisdiccional- en relación con el respeto a la autonomía local. ${ }^{4}$ Asimismo, desde la vertiente funcional, se insiste en la necesidad de llevar a cabo una más intensa descentralización desde los Länder al nivel local de gobierno (Kommunalisierung). Finalmente, no podemos olvidar que la última gran reforma del federalismo alemán (aprobada en dos fases sucesivas en 2006 y 2009) ha incidido también en la relación constitucional de los gobiernos locales con la Federación, en la medida en que se ha prohibido expresamente a ésta la transferencia directa por ley federal de competencias a aquellos, abogando así por un claro reforzamiento de la autonomía local.

Parece, pues, este un buen momento para recuperar -y actualizar- las reflexiones acerca de la posición jurídico-institucional de los entes locales en la actual República Federal de Alemania. Para ello, partiremos, como no puede ser de otro modo, además de los principales trabajos doctrinales en la materia, de las ya conocidas disposiciones constitucionales previstas en la Grundgesetz, de la jurisprudencia del Tribunal Constitucional federal que las interpreta, así como de las líneas principales de las Constituciones de los Länder (Landesverfassungen) y de algunas recientes decisiones de sus respectivos tribunales constitucionales, habitualmente menos comentadas entre nosotros, pero significativamente relevantes en los debates actuales.

De acuerdo con su configuración constitucional vigente, los entes locales son parte del Estado (en sentido amplio), en tanto en cuanto ejercen el poder público estatal, que se encuentra descentralizado territorialmente y que en última instancia deriva del pueblo (apartado 2). Bajo el concepto de entes locales (Kommunen) se agrupa en Alemania un conjunto de personas jurídico-públicas, distintas, por tanto, de la Federación y de los Länder, cuyas principales manifestaciones -municipios y Kreise- tienen garantizada constitucionalmente su legitimación democrática directa (apartado 3) y su autonomía, en los términos del art. 28.2 de la Ley Fundamental y de las respectivas constituciones de los Länder (apartado 4). Como resultado de la concepción constitucional del Estado federal alemán, los entes locales forman parte de la organización de los Länder (apartado 5). Y, en consecuencia, en cuanto al reparto constitucional de competencias entre la Federación y los Länder, son estos quienes ostentan la competencia legislativa y ejecutiva sobre el régimen local (Kommunalrecht), así como quienes deciden fundamentalmente sobre la dotación financiera de los entes locales y ejercen su tutela administrativa, produciéndose una estrecha vinculación entre ambos niveles administrativos. Trazados, a grandes rasgos, los elementos esenciales de la actual posición jurídico-constitucional de los entes locales en Alemania, profundizamos a continuación en cada uno de ellos, para acabar con una valoración general sobre el papel que aquella desarrolla en la articulación de los diversos modelos de gobierno local que se dan lugar en un marco federal como el alemán (apartado 6).

4 Sobre esta cuestión, Gracia Retortillo, R. (2010), “El nivel supramunicipal de gobierno local en Alemania”, Revista d'estudis autonòmics i federals, 11: 83-141. 


\section{LA INSERCIÓN DE LOS ENTES LOCALES EN EL ESTADO FEDERAL: PLANTEAMIENTO}

En la tradicional contraposición entre Estado y sociedad, no hay duda hoy de que los entes locales son "Estado" y forman parte de su organización administrativa. 5 Separándose de sus precedentes constitucionales anteriores, la Ley Fundamental de 1949 deja claro que los entes locales no ocupan una posición iusfundamental frente al Estado sino que constituyen ellos mismos una parte de él ("ein Stück Staat"). ${ }^{6}$ Y que, en consecuencia, no pueden ser titulares de derechos fundamentales, sino que están obligados a su respeto y protección.7 Así se deriva, por un lado, de una extendida interpretación sistemática del texto constitucional, según el cual la autonomía local viene garantizada en el capítulo segundo de la Ley Fundamental ("Der Bund und die Länder") y no entre los derechos fundamentales, a diferencia de lo que sucedía en la Constitución de Weimar, cuyo artículo 127 recogía el derecho de los municipios y agrupaciones de municipios a su autoadministración dentro del conjunto de derechos y libertades regulados en su parte segunda. Adicionalmente, el argumento sistemático viene confirmado tanto por motivos de carácter teleológico, en la medida en que la finalidad de los derechos fundamentales no es la de proteger ámbitos administrativos sino libertades individuales, como por la previsión específica en sede constitucional del recurso en defensa de la autonomía local (art. 93.1.4 ${ }^{\circ} \mathrm{GG}$ ), que poco tiene que ver con el recurso de amparo protector de derechos fundamentales. ${ }^{8}$

Según su concepción actual, los entes locales ejercen, pues, el poder público estatal (Staatsgewalt). Y lo hacen, en concreto, como expresión la descentralización territorial a la que dicho poder se halla sometido. La descentralización supone, por tanto, en oposición a la desconcentración, la transferencia de tareas a las diversas personas jurídico-públicas dotadas de autonomía (Corporaciones, Establecimientos y Fundaciones de Derecho Público). Como veremos, municipios y Kreise son, en consecuencia, corporaciones de Derecho público de carácter territorial a las que la Constitución federal garantiza autonomía para el cumplimiento de las tareas que, como tales poderes públicos, les son atribuidas.

Los términos de la inserción del gobierno local en el Estado federal alemán se completan con lo que la doctrina ha venido a definir como el doble papel (DoppelroIle) de los entes locales -principalmente, municipios y Kreise- en el seno del ordena-

5 Schmidt-Aßmann, E. y Röhl, H.C. (2008), “Kommunalrecht”, en Schmidt-Aßmann, E. y Schoch, F. (dirs.), Besonderes Verwaltungsrecht, $14^{\mathrm{a}}$ ed. Berlín: De Gruyter Recht, p. 20; Bovenschulte, A. (2000), Gemeindeverbände als Organisationsformen kommunaler Selbstverwaltung. Baden-Baden: Nomos, p. 497. Entre la jurisprudencia, por todas, BVerfGE 83, 37, 53 y ss.; BVerfGE 107, 1, 11-12. También en la legislación de régimen local encontramos plasmaciones de la "estatalidad" de los entes locales. Especialmente, en cuanto al municipio, que es frecuentemente definido como "base y parte del Estado".

6 Dreier, H. (2006), “Art. 28”, en Dreier, H. (dir.), Grundgesetz Kommentar, Vol. II, $2^{\text {a }}$ ed. Tübingen: Mohr Siebeck, p. 644.

7 Bovenschulte (2000): 506 y ss.; Dreier, H. (2006): 644.

8 P Tettinger, P. (2000), “Artikel 28 GG", en Mangoldt et. al. (dirs.), Bonner Grundgesetz Kom-

14 mentar, Vol 2 (Art. 20-78), $4^{\mathrm{a}}$ ed. Múnich: Franz Vahlen, p. 706 y 707. 
miento alemán. ${ }^{9}$ Por un lado, los entes locales se integran, como acabamos de ver, en la organización del Estado en su conjunto ("als Teil organisierter Staatlichkeit"), ${ }^{10} \mathrm{si}$ bien, lo hacen, según los términos en que viene configurada la estructura territorial del Estado, como parte de la organización institucional de los Länder, estableciendo así con ellos una intensa relación. No obstante, hay que tener en consideración que dicha integración no se produce en el sentido de la jerarquía organizativa, sino que, contrariamente, la descentralización del Estado comporta que el poder público se ejerza en el ámbito local a partir de entidades administrativas autónomas (selbständigte Verwaltungsträger), que son a su vez manifestación del principio democrático, que -en sus principales manifestaciones municipios y Kreise- se expresa a través de órganos de elección directa. Veamos, a continuación, con más detalle el alcance de cada uno de estos rasgos configuradores, empezando precisamente por la última de las consideraciones.

\section{LA GARANTÍA CONSTITUCIONAL DEL PRINCIPIO DEMOCRÁTICO EN EL NIVEL LOCAL}

Sin perjuicio de su integración en la organización de los Länder, a la que haremos referencia más adelante, la posición jurídico-institucional de los entes locales en Alemania se explica fundamentalmente, como ya hemos avanzado, por su legitimación democrática y su autonomía en el conjunto del Estado federal.

En efecto, la Ley Fundamental ha optado -siguiendo la ya clásica formulación del Tribunal Constitucional Federal- por una estructura estatal que organiza su democracia a partir de corporaciones dotadas de autonomía ("auf Selbstverwaltungskörperschaften gegliederte Demokratie"). ${ }^{11}$ En la medida en que los entes locales son parte de la organización estatal y que ejercen el poder estatal como sujetos administrativos, su legitimación democrática solo puede derivarse del titular último del poder público estatal, esto es, del pueblo, en los términos del artículo 20.2.I GG en conexión con el 28.1 GG. ${ }^{12}$ Es por ello que este último precepto recoge la llamada cláusula de homogeneidad, según la cual, "los Länder, los municipios y los Kreise deberán contar con una representación basada en elecciones generales, directas, libres, iguales y secretas”.

Como reacción al régimen nacionalsocialista, el constituyente alemán pretendió asegurar el principio democrático en todo el Estado y, por tanto, también en el nivel local. ${ }^{13}$ Con la extensión de la exigencia de legitimación democrática no solo a los Länder

9 Schmidt-Aßmann y Röhl (2008): 21. También Schoch, F. (2001), "Der verfassungsrechtliche Schutz der kommunalen Selbstverwaltung”, Jura, 2: 123 y Pielow, C. (1993), Autonomía Local in Spanien und kommunale Selbstverwaltung in Deutschland. Múnich: Franz Vahlen, p. 217.

10 BVerfGE 52, 95 (112); 79, 127 (149).

11 BVerfGE 52, 95 (112); 79, 127 (149).

12 Schoch (2001): 123; Schmidt-Aßmann y Röhl (2008): 21. El art. 20.2.I GG dispone que: “Todo poder del Estado emana del pueblo."

13 Pielow (1993): 217. 
sino también a municipios y Kreise, se asegura la unidad democrática del Estado y de su administración pública ${ }^{14}$ y se impone que, también en el nivel local, la población cuente con una representación democrática directa. En este sentido, no hay diferencias cualitativas en cuanto a la legitimación democrática de los órganos representativos de los entes locales (municipios y Kreise) y la de los de ámbito estatal (sean de los estados o de la Federación), si bien es cierto que la legitimidad democrática en el ámbito local goza de algunos elementos propios, como la mayor proximidad al ciudadano. ${ }^{15}$

Los entes locales se erigen, por tanto, en elementos esenciales para construir la "democracia desde abajo hacia arriba" ("Demokratie von unten nach oben"). ${ }^{16}$ Expresión esta que ha hecho fortuna para destacar el papel fundamental que la autonomía local desarrolla en el conjunto de la estructura del Estado alemán, como garantía y refuerzo de la democracia, de tal manera que, por ejemplo, son varias las constituciones de los Länder que la han previsto expresamente en su articulado como manera de proteger dicho vínculo entre autonomía y democracia locales (art. 11.4 de la Constitución de Baviera y art. 3.2 de la Constitución de Mecklemburgo-Pomerania Occidental). ${ }^{17}$ Adicionalmente, las constituciones de algunos Länder prevén también determinados principios o reglas en materia electoral que completan la garantía del carácter democrático de las entidades locales. Así, por ejemplo, se especifica la necesaria elección directa del Alcalde y del Landrat $^{18}$ o se prevé la posibilidad de un régimen especial asambleario para los municipios pequeños. ${ }^{19}$ En cualquier caso, la mayoría de constituciones remiten la legislación de las cuestiones electorales a una ley ordinaria específica.

\section{LA GARANTÍA CONSTITUCIONAL DE LA AUTONOMÍA DE LOS ENTES LOCALES}

Junto a la legitimación democrática, el segundo de los elementos en el que se fundamenta la integración de los entes locales en el conjunto del Estado alemán es el de su "autoadministración" o autonomía (Selbstverwaltung), que cuenta en Alemania -siguiendo su tradición histórica más reciente- con protección de rango constitucional. La Ley Fundamental reconoce, en su art. 28.2, la garantía de la autonomía de los municipios y de las agrupaciones de estos. Reconocimiento que -conviene destacarlo ya- la configura como una garantía mínima (Mindestgarantie), cuyo alcance

14 BVerfGE 83, 37, (54 y ss.).

15 En concreto, Schmidt-Aßmann y Röhl apuntan la necesidad de que este sistema de legitimación de la administración local atienda a la proximidad al ciudadano, a su visión de conjunto, flexibilidad y espontaneidad (Bürgernähe, Überschaubarkeit, Flexibilität und Spontanität). Véase Schmidt-Aßmann y Röhl (2008): 21.

16 BVerfGE 79, 127, (149).

17 Mientras en el caso de Baviera, tal afirmación se refiere en exclusiva a la autonomía municipal, la constitución de Mecklemburgo-Pomerania Occidental se extiende tanto a municipios como Kreise.

18 Art. 50.1 Verf RhPf. El Landrat (o Consejero Estatal) es el órgano unipersonal que se sitúa en la cúspide de la administración del Kreis y ostenta su representación externa y dirección interna. En la actualidad, se encuentra generalizada en la mayoría de Länder su elección directa por los ciudadanos.

19 Art. 89 Verf Sachs-An y art. 95 Verf Thür, entre otros. 
debe ser respetado y nunca reducido, por las constituciones de los Länder, que, sin embargo, pueden, como suele suceder en la práctica, completar e incluso reforzar notablemente dicha garantía. Es por este motivo que el análisis del contenido y alcance de la autonomía local requiere distinguir, en primer término, la regulación contenida en la Ley Fundamental, para, seguidamente, exponer los aspectos principales de las constituciones de los Länder en relación con dicha cuestión.

\subsection{La garantía de la autonomía local en la Ley Fundamental}

La declaración central relativa a la autonomía local se contiene en el apartado segundo del ya citado artículo 28 GG. De ahí que reproduzcamos literalmente su contenido, que reza como sigue:

"Debe garantizarse a los municipios el derecho a regular bajo su propia responsabilidad, dentro del marco de las leyes, todos los asuntos de la comunidad local. Las agrupaciones de municipios tienen igualmente, dentro del ámbito de sus competencias legales y de acuerdo con las leyes, el derecho a su autonomía. La garantía de la autonomía abarca también las bases de la propia responsabilidad financiera; a estas bases pertenece una fuente impositiva que, junto con el derecho al establecimiento del tipo de gravamen, corresponde al municipio y que se rige por la respectiva capacidad económica". ${ }^{20}$

\subsubsection{Titulares de la autonomía: municipios y agrupaciones de municipios}

La protección del artículo 28.2 GG se dirige a municipios (Gemeinden) y agrupaciones de municipios (Gemeindeverbände), si bien, como advierte ya la misma literalidad del precepto, el alcance e intensidad de la garantía es distinto para ambos titulares. Más allá de esta última constatación, a la que luego prestaremos atención, lo relevante ahora es delimitar cuáles son las entidades sobre las que se proyecta dicha garantía en la Constitución federal. De entrada, la Ley Fundamental no ofrece ninguna definición de lo que debe entenderse por municipios o por agrupaciones de municipios, dando por supuestos ambos conceptos. Ausencia que, si bien en el caso de los municipios es fácilmente salvable, atendiendo a su concepción histórica y especialmente a la unidad de dicha categoría jurídica, se hace de más difícil resolución en el supuesto de las agrupaciones de municipios, dada la pluralidad de entidades que pueden incluirse en ella.

Si nos detenemos, pues, en el término "agrupación de municpios", ${ }^{21}$ hay que partir de la multiplicidad de usos distintos -e incluso contradictorios- a que se some-

20 La traducción de este así como del resto de preceptos que se citan en adelante en el texto son nuestras.

21 Su plasmación en la Ley Fundamental de Bonn de 1949 se explica por motivos históricos, recibiendo de nuevo una clara influencia del artículo 127 de la Constitución de Weimar, que ya recogía este término como titular, junto al municipio, del derecho a la autoadministración. Sobre el origen y su evolu- 
te habitualmente dicho concepto en el lenguaje jurídico. ${ }^{22}$ Quizá ello explique las dificultades que han tenido hasta ahora la doctrina y jurisprudencia alemanas para clarificar suficientemente su significado. Los múltiples esfuerzos llevados a cabo pueden reconducirse a dos acepciones principales, según se opte por un concepto amplio o estricto.

En un sentido amplio, se entiende por "agrupación de municipios" cualquier corporación local que actúa territorialmente por encima del nivel municipal (Ortsgemeinde).23 En este concepto se incluyen, pues, tanto las corporaciones supramunicipales cuyos miembros son los habitantes, que eligen directamente a sus representantes, como aquellas en las que sus miembros son -como parece sugerir la propia literalidad del término- ${ }^{24}$ los propios municipios. Aquí pueden incluirse tanto los Kreise, como los denominados "municipios-conjuntos" (Samtgemeinden y Verbandsgemeinden) y las comunidades administrativas (Verwaltungsgemeinschaften), que actúan en el territorio inferior al del Kreis, o las agrupaciones locales superiores (Höhere Kommunalverbände), que incluyen a un conjunto de entidades de ámbito territorial superior al del Kreis y que existen en determinados Länder por motivos más bien históricos. También podríamos incluir en este concepto amplio otras corporaciones locales de Derecho público como las diferentes entidades de carácter metropolitano (Stadt-Umland-Verbände), las mancomunidades locales (Zweckverbände), creadas para el ejercicio de determinadas competencias sectoriales, o las corporaciones locales de planificación regional (Regionalkörperschaften). ${ }^{25}$

En cualquier caso, la doctrina suele convenir que el sentido del término en el art. 28.2 GG es mucho más restringido que el que acabamos de apuntar, de tal manera que los elementos de la definición anterior son condición necesaria pero no suficiente para que a una agrupación de municipios le sea atribuida la protección de la autonomía en los términos de la Ley Fundamental. No obstante, aunque la acepción constitucional de "agrupación de municipios" tiene ciertamente un carácter más estricto, su alcance no es ni mucho menos unívoco. Tanto el Tribunal Constitucional Federal como la mayoría de la literatura coinciden en que el concepto del art. 28.2.II GG es un "concepto general (Sammelbegriff) para una multiplicidad de organizaciones

ción a partir del más genérico "Kommunalverband” (agrupación local), puede verse Von Unruh, G.C. (1972), “Der Kreis - Ursprung, Wesen und Wandlungen”, en AAVV., Der Kreis, Vol. I. Colonia-Berlín: Grote, p. 11-47. Y entre nosotros, Esteve Pardo, J. (1991), Organización supramunicipal y sistema de articulación autonómica y orden local. La experiencia de la RFA. Bases y perspectivas en España. Barcelona: Civitas -Diputació de Barcelona, p. 111-113.

22 Así se pone de manifiesto en los principales trabajos doctrinales que han tratado esta cuestión, mediante múltiples supuestos de las diferentes legislaciones y constituciones de los Länder. Por todos, Bovenschulte (2000): 81 y ss.; Oebbecke, J. (1984), Gemeindeverbandsrecht Renania-Westfalia. Eine systematische Darstellung. Münster: Deutscher Gemeindeverlag - W. Kohlhammer, p. 1.

23 Gönnenwein, O. (1967), Derecho municipal alemán. Madrid: IEAL, p. 377; E Schmidt-Aßmann y Röhl (2008): 120-122; Bovenschulte (2000): 87-94.

24 El término "Verband" significa literalmente asociación o unión.

25 Sobre la naturaleza, organización y ámbito competencial de todas estas entidades, véase Gracia 18 Retortillo (2010): in totum. 
locales", ${ }^{26}$ que, por tanto, puede incluir a más de un tipo de agrupación de municipios. De entre la diversidad de propuestas que han intentado concretar una definición de dicho concepto, ${ }^{27}$ las características citadas más habitualmente suelen ser su carácter de corporación territorial y la atribución de un haz importante de competencias propias en régimen de autonomía. En consecuencia, existe total consenso acerca de que el Kreis goza de tal condición, mientras que suelen excluirse mayoritariamente las entidades cuya finalidad es el ejercicio de competencias funcionales o "ad hoc", como las mancomunidades y algunos tipos de agrupaciones metropolitanas.

\subsubsection{Contenido y alcance de la garantía de la autonomía local. Sus diferentes dimensiones}

La construcción jurídico-dogmática de la autonomía local en Alemania deriva de la intensa labor doctrinal y jurisprudencial llevada a cabo hasta nuestros días desde antes incluso de la promulgación de la Ley Fundamental de Bonn en 1949. Como ya hemos destacado, el punto de partida de la Constitución alemana en esta cuestión es el organizativo, y, a diferencia de sus predecesoras, el reconocimiento de la autonomía local no se sitúa entre los derechos fundamentales, sino como parte de la organización del Estado. El cambio histórico en la sistemática constitucional supone confirmar lo que ya se había venido sosteniendo desde doctrina y jurisprudencia a partir de la época de Weimar y concebir así la autonomía local como una "garantía institucional".

En efecto, a pesar de algunos sólidos intentos de construcciones alternativas ${ }^{28}$ y de las críticas que todavía hoy se vierten sobre ella, ${ }^{29}$ la concepción de la autonomía local que sigue imponiéndose entre la doctrina alemana contemporánea es la de su configuración como una garantía institucional, de acuerdo con la concepción de C. Schmitt. ${ }^{30}$ Sin detenernos en el sentido y contenido de esta teoría, puesto que,

26 BVerfG 52, 95, 111; BVerfGE 79, 127, 151. No obstante, hay que tener en cuenta que la primera de las sentencias -cuyos términos se reiteran en la segunda- parte del análisis del concepto de agrupación de municipios en relación con la Constitución del Land de Schleswig-Holstein y no respecto del art. 28.2 GG. En este caso, el BVerfG negó la condición de Gemeindeverband al Amt, agrupación supramunicipal de ámbito territorial inferior al del Kreis recogida en la organización territorial de varios Länder del norte de Alemania.

27 Una exhaustiva recopilación en Bovenschulte (2000): 429-479.

28 Burmeister, J. (1977), Verfassungstheoretische Neukonzeption der kommunalen Selbstverwaltung. Múnich: Vahlen. Burmeister propuso considerar la autonomía local únicamente como un principio constitutivo de la organización estatal, de modo que los entes locales quedarían como la última instancia ejecutiva de las tareas estatales, sin que les correspondiera una garantía de competencias o funciones. Por otra parte, a principios de la década de los 70, la llamada teoría funcional (funktionale Selbstverwaltungsverstädnis) había pretendido sustituir la garantía de la "propia responsabilidad” municipal por la garantía de una participación municipal en los procesos decisorios de las instancias superiores.

29 Especialmente crítico con los aspectos metodológicos, Bull, H.P. (2008), “Kommunale Selbstverwaltung heute - Idee, Ideologie und Wirklichkeit”, Deutsches Verwaltungsblatt, 1: 1-11.

30 Dirigida, por tanto, a impedir la supresión por el legislador de determinadas instituciones contenidas en el texto constitucional. C. Schmitt enunció por primera vez su teoría de las garantías institucionales en su Verfassungslehre de 1928 (hoy reeditada por Duncker-Humblot, Berlín, 1965). Posteriormente, la 
como es sabido, su temprana traslación por vía doctrinal y jurisprudencial al ordenamiento español las ha hecho ya suficientemente conocidas entre nosotros, ${ }^{31}$ sí conviene poner de relieve la evolución que han sufrido algunos de sus elementos y cuál es su vigente interpretación. ${ }^{32}$

De acuerdo con la ya clásica descripción de K. Stern, 33 la literatura alemana distingue tres niveles sobre los que se proyecta la garantía de la autonomía local: primero, una garantía institucional de carácter subjetivo (institutionelle Rechtssubjektsgarantie); segundo, una garantía de carácter estrictamente institucional o jurídico-objetiva (objektive Rechtsinstituionsgarantie); y, finalmente, la garantía de una posición jurídico-subjetiva de sus titulares (subjektive Rechtsinstitutionsgarantie).

\subsubsection{Dimensión subjetiva de la garantía de la autonomía local}

En términos generales, la dimensión subjetiva de la garantía de la autonomía local protege la existencia necesaria de los sujetos jurídicos "municipios" y "agrupaciones de municipios" en tanto que instituciones integrantes de la estructura administrativa del Estado. De ello se deriva, en primer lugar, que los municipios y sus agrupaciones deben configurarse como corporaciones de Derecho público, y por tanto, como personas jurídico-públicas organizadas en torno a un conjunto de miembros, que ejercen competencias públicas, sometidas a control estatal. ${ }^{34}$ Complementariamente, se garantiza su carácter territorial, en la medida en que dichas instituciones son corporaciones cuyos miembros (la población) se identifican por su conexión a un territorio común. Con todo, no se protege la subsistencia de cada uno de los municipios y agrupaciones existentes en un momento dado, ya que la finalidad

completó en Freiheitsrechte und institutionelle Garantieen der Reichsverfassung, de 1931 (hoy en Verfassungsrechtliche Aufsätze. Berlín: Duncker-Humblot, 1973).

31 Parejo Alfonso, L. (1981), Garantía institucional y autonomías locales. Madrid: IEAL; Embid Irujo, A. (1980), “Autonomía local y Constitución: aproximación al concepto y significado de la declaración constitucional de autonomía municipal”, Revista Española de Derecho Administrativo, 30: 437-470. No obstante, como es sabido, tal teoría no ha estado exenta de críticas y de ahí sus diferentes propuestas de reformulación. La principal es la conocida como garantía constitucional de la autonomía local, defendida ya, entre otros, por García Roca, J. (1985), “La autonomía del Derecho político municipal. Fundamentos dogmáticos de la Constitución Española”, en AAVV, Organización territorial del Estado. Madrid: IEF, p. 1406 y ss.; y posteriormente desarrollada por García Morillo, J. (1998), La garantía constitucional de la autonomía local. Madrid: Marcial Pons - Diputación de Barcelona. Los debates más recientes entre nosotros, en los trabajos de los profesores Carro y Velasco en el libro AAVV. (2007), Autonomía Municipal. Administración y Regulación Económica. Títulos Académicos y Profesionales. Actas del II Congreso de la Asociación de Profesores de Derecho Administrativo. Pamplona: Thomson-Aranzadi - AEPDA.

32 Al respecto, una excelente puesta al día de esta cuestión en la reciente obra colectiva Velasco Caballero, F., dir., (2010), Gobiernos Locales en Estados federales y descentralizados: Alemania, Italia y Reino Unido. Barcelona: Institut d'Estudis Autonòmics.

33 Stern, K. (1977), Das Staatsrecht der Bundesrepublik Deutschland, Vol I. Múnich: CH Beck. La misma distinción en Velasco Caballero (2010): 57 y ss.

34 Sobre el actual concepto de "corporación de Derecho público" en el Derecho alemán, véase, por ejemplo, Maurer, H. (2009), Allgemeines Verwaltungsrecht, $17^{\text {a }}$ ed. Múnich: CH Beck, p. 598 y ss. 
de la garantía no es individual, sino, por esencia, institucional. Lo que se prohíbe es más gráficamente- la eliminación de todo, o la parte esencial, del nivel administrativo municipal o supramunicipal..$^{35} \mathrm{El}$ art. 28.2 GG no impide, por tanto, las supresiones, las fusiones o cualquier otra alteración territorial de municipios o agrupaciones de municipios concretos. De todos modos, sí se ha derivado de este precepto una cierta protección de los entes locales individualmente considerados. Así, por ejemplo, se exige que dichas modificaciones territoriales solo pueden llevarse a cabo por causas de interés general y con audiencia de los entes locales afectados. Por último, se garantiza también el derecho al nombre de cada uno de los municipios (y agrupaciones), como elemento de su individualización respecto al resto.

Llegados a este punto, podrá observarse fácilmente que la dificultad aquí no reside tanto en la determinación del contenido de esta dimensión subjetiva de la garantía como de nuevo en la identificación del objeto (o mejor dicho, sujeto) sobre el que se proyecta. Como ya hemos dicho, mientras la referencia al municipio en el art. 28.2.I GG es clara al ser esta una categoría unitaria de entre las corporaciones locales de carácter territorial, la mención a las "agrupaciones de municipios" en el segundo inciso del mismo artículo 28.2 GG no aclara cuál o cuáles de entre la pluralidad de entidades que pueden entenderse comprendidas en él goza(n) de la protección constitucional.

De entrada, sería posible entender que la Ley Fundamental optó conscientemente por no garantizar una agrupación de municipios en concreto, puesto que, si bien su art. 28.1.II se refiere expresamente al Kreis, el 28.2.II GG renuncia a su mención, recogiendo un concepto "paraguas" como el ya conocido de "agrupación de municipios". ${ }^{36}$ Sin embargo, dicha conclusión debe ser rápidamente descartada, ya que existe absoluta unanimidad entre la doctrina alemana ${ }^{37}$-a la que se añade reiterada jurisprudencia constitucional- en que el art. 28.2.II GG garantiza la necesaria existencia del Kreis en la organización territorial de todos los Flächenländer. ${ }^{38}$ Los argumentos alegados para ello son de distinto calado. Desde una perspectiva histórica, se atiende a la importancia del Kreis en la tradición organizativa alemana, que habría hecho que el constituyente de 1949 hubiese dado ya por sentada su

35 Kluth, W. (2004), "Die kommunale Selbstverwaltung", en Wolff, H. et al., Verwaltungsrecht. Vol. 3, $5^{\text {a }}$ ed. Múnich: C.H.Beck, p. 645. Particularmente interesantes resultan estas consideraciones, como veremos más adelante, en los procesos de reforma territorial y funcional emprendidos sobre el Kreis en diversos Länder en los últimos años.

36 Así lo hace notar Tettinger (2000): 608 y ss.

37 Por ejemplo, Pieroth, H.D. (2006), “Art. 28”, en Jarass, B. y Pieroth, H.D. (dirs.), GG: Grundgesetz für die Bundesrepublik Deutschland. Kommentar, 8a ed. Múnich: CH Beck, p. 570; Burgi, M. (2008), Kommunalrecht, $2^{\text {a }}$ ed. Múnich: CH Beck, p. 304-305; Schmidt-Aßmann y Röhl (2008): 115; Dreier (2006): 558; Tettinger (2000): 608. Y las sentencias citadas por todos ellos.

38 Por tanto, con la excepción de las Ciudades-Estado de Berlín, Bremen y Hamburgo, que no cuentan con dicha división territorial, debido a sus peculiaridades político-institucionales. Otra peculiaridad en cuanto a la generalización de los Kreise es la existencia de las llamadas ciudades libres de Kreis (Kreisfreie Städte), municipios no integrados en ningún Kreis, en atención a sus características poblacionales. Su existencia se admite sin fisuras y no se plantea ningún impedimento constitucional para ello. 
existencia. ${ }^{39}$ Asimismo, se alega que la garantía del Kreis supone una protección indispensable de la autonomía municipal, especialmente en las zonas rurales y menos pobladas, que no puede dejarse a la decisión del legislador ordinario..$^{\circ}$ De todos modos, el argumento más concluyente -o al menos el más extendido en la actualidad- parece ser el sistemático. Es precisamente la referencia al Kreis en el apartado primero del propio artículo 28 GG la que conduce a afirmar que, si hay una agrupación de municipios que debe ser garantizada institucionalmente, ese es el Kreis, puesto que, como ya hemos visto, la Ley Fundamental le exige precisamente a él -y sólo a él entre las agrupaciones municipales- que cuente necesariamente con una representación democrática directa. ${ }^{41}$

Más allá del Kreis, no puede identificarse entre la doctrina alemana una opinión mayoritaria acerca de la posibilidad de incluir o no otras agrupaciones de municipios en la garantía constitucional del artículo 28.2 GG y, menos aún, sobre cuáles deberían ser, en su caso, dichas entidades. Baste por ahora señalar que, ante la ambigüedad de la Ley Fundamental en este aspecto, será indispensable prestar atención a las previsiones de las constituciones de los Länder (y a la jurisprudencia de sus respectivos tribunales constitucionales), que juegan un papel crucial en la configuración de la planta organizativa supramunicipal. ${ }^{42}$

\subsubsection{Dimensión objetiva de la garantía de la autonomía local}

Desde una perspectiva objetiva, se protege la institución de la "autonomía" o "autoadministración" (Selbstverwaltung), esto es, el ejercicio de un ámbito propio de competencias bajo la propia responsabilidad. Dos son los elementos esenciales que componen, pues, esta garantía: por un lado, la existencia de un ámbito de competencias (Aufgabenbestand) y, por otro, su ejercicio bajo la propia responsabilidad (Eigenverantwortlichkeit). ${ }^{43}$ Adicionalmente, ambos elementos están sometidos a una reserva de ley, que perfecciona a la vez que limita el alcance de esta garantía de la autonomía local en su vertiente objetiva. El análisis de estos elementos, especialmente el relativo a las competencias, arroja la conclusión de que es precisamente esta dimensión objetiva la que explica buena parte de la distinta intensidad de la garantía del artículo 28.2 GG para municipios y agrupaciones de municipios. ${ }^{44}$ Veamos cada uno de estos tres aspectos con más detalle.

39 El argumento histórico, entre otros, en Wiese, R. (1972), Garantie der Gemeindeverbandsebene? Frankfurt Main: Athenäum Verlag, p. 29. Sobre la importancia histórica del Kreis, véase Von Unruh (1972): 11-47; Esteve Pardo (1991): 41 y ss.

40 Wiese (1972): 29.

41 Schmidt-Aßmann y Röhl (2008): 115; Burgi (2008): 304-305; Dreier (2006): 558; Tettinger (2000): 608; Pieroth (2008): 570. Sobre la cláusula de homogeneidad, recuérdese lo dicho en el apartado 3.

42 Esteve Pardo (1991): 146-150. A ello nos referiremos al tratar la regulación de la autonomía local en las constituciones de los Länder en el apartado 4.2.

43 Burgi (2008): 60 y ss.; Schoch (2001): 121 y ss.

44 Veamos cada uno de estos tres aspectos con más detalle. 
a) Si nos referimos, en primer término, al reconocimiento de un ámbito de competencias propias o autónomas, la dicción del primer y el segundo incisos del artículo 28.2 GG determinan ya un marco jurídico de partida distinto para los municipios y las entidades supramunicipales. Mientras a los primeros se les garantiza el llamado principio de universalidad (Allzustädigkeit), al atribuírseles la gestión de "todos los asuntos de la comunidad local" ("alle Angelegenheiten der örtlichen Gemeinschaft"), para los Kreise y el resto de agrupaciones de municipios incluidas, en su caso, en la esfera del art. 28.2.II GG, la garantía se limita al "ámbito de sus competencias legales" ( "gesetzliche Aufgabenbereich").

En virtud del principio de universalidad, el municipio tiene garantizada constitucionalmente la capacidad para asumir -sin necesidad de título competencial específico- todas las tareas que se definan como asuntos de la comunidad local y que no estén atribuidas previamente a otros sujetos administrativos, lo que incluye además el Ilamado derecho a la espontaneidad (Recht der Spontanität), es decir, la facultad para asignarse actividades materiales nuevas dentro de las condiciones anteriores. ${ }^{45}$ Más allá de las dificultades existentes para determinar lo que debe entenderse por "asuntos locales", ${ }^{46}$ expresión que actúa simultáneamente como habilitación y límite del marco de actuación municipal (Verbandskompetenz), conviene señalar que el principio de universalidad del artículo 28.2.I GG no impide que, en ejercicio de la reserva de ley prevista por el propio precepto, el legislador asigne los asuntos locales a otras entidades públicas locales, sino que simplemente le impone límites a la hora de hacerlo, teniendo en cuenta esta suerte de "presunción de competencia" municipal. ${ }^{47}$ Esto obliga, pues, al legislador a justificar aquellas medidas en que atribuya a una administración no municipal una competencia que se incluya entre los asuntos propios de la comunidad local, pero también aquellas en que imponga al municipio competencias que no tienen carácter local o bien que, teniéndolo, no querían ser asumidas por el municipio en virtud de su universalidad. ${ }^{48}$

Contrariamente, las agrupaciones de municipios titulares de la autonomía constitucional no se benefician del principio de universalidad, sino que a ellos la Ley Fundamental les garantiza únicamente la existencia de las competencias que la ley les asigne. No quiere decirse con ello que el legislador pueda optar libremente por atribuirles o no competencias, sino que

45 Dreier (2006): 658; Tettinger (2000): 723; E Schmidt-Aßmann y Röhl (2008): 27.

46 De acuerdo con el BVerfG se entiende que son "asuntos de la comunidad local": "aquellas necesidades que crecen en la comunidad local o que en relación a ella tienen una especial significación, esto es, que afectan a los ciudadanos municipales en cuanto tales en su vida colectiva y/o como comunidad política." (BVerfG 79, 127 [146]).

47 Dreier (2006): 658.

48 Burgi (2008): 60-62. 
las agrupaciones de municipios incluidas en el artículo 28 II.2 GG deben sobre ello existe también un amplio consenso- disponer de un mínimo de competencias autónomas en el ámbito supramunicipal. ${ }^{49}$ La dificultad reside, sin duda, en determinar cuál sea ese mínimo competencial, así como la articulación funcional de estas entidades con el municipio. En los últimos años ha sido precisamente la cuestión de la delimitación de las competencias de los entes supramunicipales, especialmente del Kreis, frente al municipio una de las cuestiones que ha ocupado mayor lugar entre la jurisprudencia y doctrina alemanas, teniendo su punto álgido en la conocida sentencia "Rastede" del Tribunal Constitucional Federal alemán..$^{50}$ En ella se refuerza la primacía del municipio en el reparto de las tareas locales y, por lo que ahora interesa, se constata que, de acuerdo con el art. 28.2.II GG, corresponde a los Kreise una función complementaria y compensatoria (o de equilibrio) de las tareas municipales (Ergänzungs- und Ausgleichsfunktion), que tiene por finalidad proteger el cumplimiento de las tareas asignadas a los municipios pertenecientes al Kreis que exceden su ámbito administrativo (Verwaltungsraum) o bien su capacidad de gestión (Verwaltungskraft). ${ }^{51}$

b) Además de la determinación de un ámbito competencial específico, la dimensión objetiva de la garantía del art. 28.2 GG exige, en segundo lugar, que el ejercicio de dichas competencias se realice "bajo la propia responsabilidad". En términos generales, con ello se garantiza un margen de actuación y configuración de los entes locales para organizarse y tomar decisiones conforme a sus propios criterios y para ejercer las tareas que tengan atribuidas sin instrucciones ni tutelas del resto de sujetos públicos, especialmente del Land. Los titulares de la autonomía deben poder decidir respecto al "si", el "cómo" y el "cuándo" en el ejercicio de sus competencias autónomas. ${ }^{52}$ Esto impide los controles de oportunidad sobre las competencias locales de su círculo de acción propio, pero no excluye, sin embargo, los controles de legalidad, puesto que, tal y como exige la Constitución, los poderes públicos se hallan sometidos a la ley y al Derecho (art. 20.3 GG).

49 BVerfGE 79, 127 (150); BVerfGE 83, 336 (383). Véase Kluth (2004): 653; Gern, A. (2003), Deutsches Kommunalrecht, $3^{\text {a }}$ ed. Baden-Baden: Nomos, p. 561; Maurer, H. (1995), "Verfassungsrechtliche Grundlagen der kommunalen Selbstverwaltung”, Deutsches Verwaltungsblatt, 19: 1046; Burgi (2008): 305.

50 BVerfGE 79, 127. Un comentario en castellano a dicha sentencia es el de F Schoch, F. (1993), "En relación a la situación de la autonomía local tras la "Sentencia-Rastede" del Tribunal Constitucional Federal”, Documentación administrativa, 234 (Ejemplar dedicado a: El Derecho administrativo en Alemania: Tendencias actuales I): 281-321.

51 BVerfGE 58, 177 (196); BVerfGE 79, 127 (152). No obstante, la doctrina ha precisado que para hablar de una verdadera "competencia" del Kreis en este u otro sentido es necesaria una norma de atribución competencial (como mínimo del tipo “cláusula general”). Así, Schoch (2001): 129.

52 Aquí habrá que distinguir entre competencias voluntarias y competencias obligatorias. En el caso de las primeras, la propia responsabilidad se extiende al "si”, al "cómo" y al "cuándo", mientras que 24 para las tareas obligatorias el primer elemento, el “si”, desparece, pero no así los otros dos. Dreier (2006): 
Vinculadas al concepto de propia responsabilidad se encuentran las denominadas "potestades básicas" (Hoheiten), con las que la doctrina alemana alude habitualmente, de forma más bien ejemplificativa que dogmática, a un conjunto de facultades sin las que no es posible el ejercicio autónomo de competencias. Tradicionalmente expuestas en sede de la autonomía municipal ( $G e$ meindehoheiten), la literatura germánica suele extender su aplicación -de manera casi automática y sin excesivas explicaciones- a las agrupaciones de municipios del art. 28.2 GG.53 Los listados habituales suelen incluir como parte de la propia responsabilidad las siguientes potestades: la potestad de planificación (Plannungshoheit), entre las que suele destacarse particularmente la de planificación urbanística (Raumplannungshoheit); la potestad en materia de personal (Personalhoheit); la potestad de (auto)organización (Organisationshoheit); la potestad normativa o de ordenanza (Rechtsetzungshoheit) y la potestad financiera (Finanzhoheit). ${ }^{54}$ Sin entrar ahora a analizar el contenido de cada una de estas potestades, ${ }^{55}$ sí debemos destacar el expreso reconocimiento que tiene la potestad financiera como parte de la autonomía local en el propio art. 28.2.III GG. Reconocimiento que, en el caso del municipio, se concreta además de manera explícita en el derecho a establecer un tipo impositivo sobre alguna de las fuentes de naturaleza impositiva ligada a la capacidad económica municipal (art. 28.2 IV GG). ${ }^{56}$ La ausencia de mención a los Kreise (y a las agrupaciones de municipios en general) en este último inciso del art. 28.2 GG, referido exclusivamente a los municipios, fundamenta el distinto alcance de la garantía constitucional de ambos tipos de entidades locales también en cuanto a su autonomía financiera.

En cualquier caso, la referencia a estas potestades reviste, como decimos, un carácter orientador respecto al contenido de la autonomía y no hay que olvidar que su eficacia jurídica requiere, en todo caso, de una expresa previsión legal, que delimite su marco concreto de actuación. ${ }^{57}$

c) El derecho a la autonomía de municipios y agrupaciones de municipios les corresponde, según el art. 28.2 GG, “en el marco de las leyes". La garantía de la autonomía local se somete, pues, a una reserva de ley, que se extiende a

53 Contrario a esta traslación es Pieroth (2008): 570.

54 En menor medida se incluye también la potestad de cooperación (Kooperationshoheit) o la potestad territorial (Gebietshoheit).

55 Para ello, puede verse cualquiera de las habituales exposiciones de carácter general citadas. P. ej., Schmidt-Aßmann y Röhl (2008): 30 y ss.

56 La redacción actual del art. 28.2 GG en cuanto a la autonomía financiera es el resultado de dos reformas constitucionales sucesivas en el tiempo. La primera tuvo lugar en 1994 (Ley de modificación constitucional de 27 de octubre) y supuso el reconocimiento expreso, conforme a lo que venía sosteniendo el Tribunal Constitucional Federal, de que la propia responsabilidad financiera formaba parte de la garantía de la autonomía local (frase III). La segunda de las reformas se produjo mediante la Ley de modificación constitucional de 20 de octubre de 1997 e introdujo la especificidad comentada en el texto para los municipios, con la finalidad de reforzar su autonomía financiera (frase IV).

57 Con matices al respecto, Esteve Pardo (1991): 145. 
todos los elementos que configuran la institución de la autonomía (competencias y propia responsabilidad). Reserva de ley que, efectivamente, cumple una función de configuración o perfeccionamiento del contenido de la autonomía, pero que a su vez encuentra límites como consecuencia de la protección constitucional otorgada por el propio artículo 28.2 GG.

El legislador recibe, pues, el encargo constitucional de delimitar el contenido y alcance de la autonomía local. En el ámbito del artículo 28.2 GG el término "ley" incluye no sólo las normas parlamentarias, sino también las de rango inferior, como reglamentos y ordenanzas..$^{58} \mathrm{Al}$ legislador competente se le atribuye la capacidad para configurar la autonomía local y con ello la posibilidad de intervenir en la existencia de las competencias locales así como en la forma de su ejercicio.

Puesto que, de otro modo, la reserva de ley podría convertirse en el "talón de Aquiles" 59 de la autonomía local, hay que tener en cuenta que el art. 28.2 GG impone límites sustantivos a la actuación del legislador y que, por tanto, no se admite cualquier configuración legal ni todo tipo de injerencia en dicha autonomía. La difícil tarea de valorar dónde se sitúan estos límites ha tenido diferentes respuestas en el tiempo por parte de la doctrina y la jurisprudencia alemanas. En atención a las similitudes con la problemática planteada en materia de derechos fundamentales, originariamente se admitió el uso de las técnicas de protección desarrolladas en dicho ámbito como la del principio de proporcionalidad (Verhältnismäßigkeit), la teoría de los límites a los límites (Schranken-Schranken) ${ }^{60}$ o la de la garantía del contenido esencial (Wesensgehalt-o Kernsbereichgarantie).

No obstante, desde la trascendental sentencia "Rastede", el Tribunal Constitucional Federal rechaza expresamente la aplicación del principio de proporcionalidad al ámbito de la garantía institucional del artículo $28.2 G^{616}$ y sostiene que la protección de la autonomía local derivada de este precepto se proyecta fundamentalmente en dos direcciones: por un lado, se mantiene la existencia de un ámbito nuclear o contenido esencial (Kernbereich o Wesens gehalt) de la autonomía local, que debe permanecer inalterado; mientras que, fuera de él (Randbereich), se introduce un principio material de carácter específico que atiende a un "reparto de tareas a favor del municipio" (gemeindespezifische materielle Aufgabenverteilungsprinzip).

58 BVerfGE 26, 228, 237; 56, 298, 309.

59 Tomando la expresión a la que se refieren tanto Schmidt-Aßmann y Röhl (2008): 29, como Dreier (2006): 664 .

60 Dreier (2006): 664.

61 Algunos autores siguen defendiendo la posibilidad de aplicar este principio al artículo 28.2 GG, teniendo en cuenta las singularidades de su concepción como garantía institucional. Véase, Burgi (2008): principio constitucional general. Dreier (2006): 666. 
De entrada, el legislador debe respetar, por tanto, el contenido esencial de la autonomía local, esto es, aquella parte de la misma que como institución no puede ser modificada sin cambiar su estructura y tipo. ${ }^{62}$ La determinación de este contenido -operación nuevamente compleja- se ha llevado a cabo a través del recurso a métodos distintos, siendo los que atienden a la "evolución histórica" así como a la "forma típica o imagen característica" de la autonomía local aquellos que la doctrina y jurisprudencia comparten más habitualmente. ${ }^{63}$

De conformidad con esta jurisprudencia constitucional, ya hemos dicho que forma parte del contenido esencial del elemento subjetivo de la autonomía el requisito de que las alteraciones territoriales que se lleven a cabo por el Estado en relación con municipios y agrupaciones de municipios del artículo 28.2 GG solo pueden tener lugar por motivos de interés general y previa audiencia de las corporaciones territoriales afectadas. Por otra parte, en cuanto a la existencia de competencias, debe advertirse que no se protege un catálogo, preciso o determinable conforme a características posteriores, de tareas locales, sino que el BVerfG únicamente incluye dentro del núcleo esencial el derecho de los municipios a asumir tareas de la comunidad local que no hayan sido atribuidas a otra instancia. Además, en relación con el ámbito de la propia responsabilidad, dicha protección prohíbe también aquellas regulaciones que tengan como resultado "asfixiar" la libre capacidad de los municipios para configurar su propia organización. De igual modo, se cuenta dentro del núcleo esencial una mínima dotación financiera. ${ }^{64}$

Por la vía del núcleo esencial se protege, pues, la autonomía local únicamente frente a determinadas -y especialmente graves- injerencias. Más allá de este núcleo, las injerencias legislativas sobre la autonomía local encuentran también limitaciones, si bien de menor intensidad y con un origen claramente distinto al de las técnicas propias de los derechos fundamentales.

En cuanto a la existencia de competencias, fuera del núcleo esencial, rige la protección del denominado "principio material de reparto de tareas a favor de los municipios", que, como ha sido enfatizado reiteradamente por la jurisprudencia, actúa también protegiendo a los municipios no solo frente al Land, sino también frente al Kreis. Lo más habitual ha sido que este principio actúe ante las medidas destinadas a la privación de competencias, si bien en los últimos años se reclama su extensión a los casos en que se da una imposición de competencias a los municipios, especial-

62 Schoch (2001): 126.

63 BVerfGE 79, 127 (146); 83, 363 (381); 86, 90 (107). Schoch (2001): 126; Pielow (1993): 238; Schmidt-Aßmann y Röhl (2008): 28-29; Dreier (2006): 665. Entre nosotros, Carro se hace eco también del "método de sustracción" según el cual el contenido esencial de la autonomía local puede extraerse de la propia intensidad de la intervención limitadora. Carro Fernández-Valmayor, J. L. (2006), “El régimen local alemán: una introducción”, en Font Llovet, T. (dir.), Anuario del Gobierno Local 2005. Barcelona: Fundación Democracia y Gobierno Local - IDP, p. 231-232.

64 Dreier (2006): 666. 
mente sin la correspondiente provisión financiera. ${ }^{65}$ De acuerdo con su concepción jurisprudencial habitual, ${ }^{66}$ este principio contiene una "regla-excepción", según la cual el legislador únicamente puede retirar competencias a los municipios por motivos de interés general, de tal modo que no sea posible asegurar de otra manera el ejercicio conforme al ordenamiento jurídico de dichas competencias. Motivos como la simplificación administrativa o la concentración de competencias no se admiten como justificación para atribuir una competencia local a otra entidad pública distinta al municipio. ${ }^{67}$ Del mismo modo los argumentos de la economicidad y el ahorro solo se admiten excepcionalmente en los supuestos en que mantener la competencia en el ámbito municipal produjese un incremento desproporcionado de los costes. ${ }^{68} \mathrm{La}$ ponderación y valoración realizada por el legislador en este reparto o distribución de tareas es revisable judicialmente, si bien en la calificación que aquel realice de una determinada tarea como local o supralocal le corresponde una margen de apreciación notable. ${ }^{69} \mathrm{Al}$ respecto, cabe apuntar que los últimos pronunciamientos jurisprudenciales han incidido -si cabe- todavía más en esta presunción competencial del municipio, especialmente frente al Kreis, de tal manera que se reitera la más limitada protección de la autonomía de los Kreise en relación con los municipios, también en el ámbito de sus competencias propias. ${ }^{70}$

En relación con la propia responsabilidad, más allá del núcleo esencial, la protección se dirige a la conservación de un "margen de actuación suficiente" (hinreichender Spielraum) de las entidades locales en el cumplimiento de sus tareas. Los tribunales ejercen aquí un control de razonabilidad (Vertretbarkeitskontrolle), cuyos límites presentan particularidades distintas respecto a cada una de las diferentes potestades locales. ${ }^{71}$

65 Lo que liga dicho principio también con el principio de conexión financiera entre ingresos y gastos, sobre el que volveremos más tarde. Véase punto 4.3.2.2.

66 BVerfGE 79, 127, 153; confirmando la anterior, BVerfGE 83, 363,382 y ss.

67 La Grundgesetz -dice el Tribunal- parte de una "asignación de tareas descentralizada", que no justifica esta privación de competencias por una mayor eficiencia administrativa (BVerfGE 79, 127, 153).

68 Interesan aquí las reflexiones de la sentencia "Rastede" al afirmar que: "una administración centralizada podría trabajar más racionalmente y de forma más barata; sin embargo, la Constitución confronta estas consideraciones económicas junto a la perspectiva político-democrática de la participación de la ciudadanía local en el cumplimiento de las tareas públicas y le da preferencia a esta última”. (BVerfGE 79, 127, 154).

69 Dreier (2006): 666.

70 En este sentido, véase la sentencia del Tribunal Constitucional Federal alemán de 20 de diciembre de 2007 (BVerfGE 119, 331-394). Dicha sentencia declaró inconstitucional, con motivo de un recurso constitucional local de varios Kreise, las Arbeitsgemeinschaften (forma de administración mixta) en el ámbito del Hartz-IV (asistencia social no contributiva) creadas conforme al Art. 44b SGB II. Aunque el principal fundamento de la sentencia se refiere a que la creación de estas entidades contradice el principio de asunción de competencias bajo propia responsabilidad, que obliga a los sujetos administrativos competentes a asumir sus competencias principalmente mediante sus propias autoridades (propio personal, propios medios materiales, propia organización), el Tribunal hace también importantes consideraciones respecto a la autonomía local. Muy crítico con esta sentencia desde la perspectiva de la autonomía local, Schoch, F. (2008), "Neukonzeption der kommunalen Selbstverwaltungsgarantie durch das Bundesverfassungsgericht?", Deustches Verwaltungsblatt, 15: 937-946.

71 Una exposición general del alcance de estos límites para las diferentes potestades municipales, 28 en Burgi (2008): 70-71; Dreier (2006): 667-675; Schoch (2001): 131-133. 


\subsubsection{Garantía de la posición jurídico-subjetiva}

El tercer elemento de la garantía institucional de la autonomía local viene a ser una garantía de los anteriores, en la medida en que se traduce en el reconocimiento de una posición jurídica subjetiva de los municipios y agrupaciones de municipios frente a eventuales ataques a su autonomía. Ello supone que los entes locales pueden exigir el respeto del artículo 28.2 GG a los destinatarios obligados a ello (principalmente, los poderes públicos alemanes, lo que incluye también a los entes locales, pero no a las instituciones comunitarias ni los privados).

En este sentido, los municipios y agrupaciones de municipios tienen abierto el recurso a los tribunales ordinarios (vía contencioso-administrativa), para defenderse frente a eventuales lesiones de su derecho a la autonomía, que efectivamente se configura no solo como un principio de la organización estatal, sino también como un derecho subjetivo. En consecuencia, sus titulares pueden exigir tanto su defensa frente a injerencias ilegítimas, como el cumplimiento de prestaciones positivas (un trámite de audiencia, de participación o el principio de comportamiento leal, entre otros). ${ }^{72}$

Más allá de la vía jurisdiccional ordinaria, la principal peculiaridad de la garantía en este caso reside en la expresa previsión en la Ley Fundamental de un recurso específico para la defensa de la autonomía local ante el Tribunal Constitucional Federal (Kommunalverfassungsbeschwerde). En efecto, de acuerdo con en el art. 93.1.4) GG y el § 91 de la Ley del Tribunal Constitucional Federal, los municipios y agrupaciones de municipios pueden recurrir ante dicho Tribunal cuando consideren lesionada la autonomía que les reconoce el artículo 28.2 GG. A pesar de que ambos preceptos se refieren a las "leyes" como posible objeto del recurso, la jurisprudencia constitucional ha interpretado el término materialmente y se admite la interposición del recurso ante normas de rango inferior a la ley. Pueden impugnarse tanto normas federales como estatales (del Land), pero siempre habrá que tener en cuenta la cláusula de subsidiariedad prevista en la propia Ley Fundamental, según la cual no podrá hacerse uso del recurso federal cuando quepa recurrir ante el Tribunal Constitucional del Land por medio de un recurso análogo previsto en su ordenamiento. Subsidiariedad que evidentemente contribuye a la reducción del número de recursos que se plantearán por esta vía ante el Tribunal Constitucional Federal.

\subsection{La garantía de la autonomía local en las constituciones de los Länder}

El alcance y contenido de la garantía de la autonomía local prevista por la Grundgesetz viene completado por las previsiones de las constituciones de los Länder al respecto, de tal manera que, como ya hemos dicho, la primera actúa en forma de ni-

$72 \operatorname{Dreier}(2006): 656$. 
vel mínimo de protección. Ambas garantías se sitúan una al lado de la otra, ${ }^{73}$ siendo sus destinatarios parcialmente distintos. Así, mientras la Federación está únicamente vinculada al artículo 28.2 GG, los poderes públicos de los estados federados (y con ellos también el conjunto de los entes locales) deben respetar tanto esa garantía de la Ley Fundamental como las previsiones de la correspondiente Constitución del Land. $^{74}$

\subsubsection{Relevancia práctica y funciones de las constituciones de los Länder en relación con la autonomía local}

Precisamente este carácter de mínimo común del artículo 28.2 GG, unido a la amplia tarea interpretativa que -como acabamos de ver- han llevado a cabo tanto el Tribunal Federal alemán como la doctrina jurídica moderna, ha conducido a una cierta estandarización en la concepción de la autonomía en el conjunto de los estados federados, lo que ha supuesto una habitual relativización de las previsiones contenidas en las Constituciones de los Länder. ${ }^{75}$ No obstante, aunque es cierto que dicha estandarización ha sido especialmente notoria en el caso de la autonomía de los municipios, ${ }^{76}$ no lo es menos que su proyección sobre las agrupaciones municipales pone de manifiesto una mayor diversidad, fruto, por otra parte, del correlativo margen que el artículo 28.2 GG deja, en relación con unos y otras, al legislador del Land. Es en este sentido que las constituciones de los Länder juegan un destacado papel a la hora de atender a la definición de la posición jurídico-institucional del nivel local supramunicipal, y especialmente en la determinación de cuáles son las agrupaciones de municipios que, junto al Kreis, forman parte de dicho nivel territorial.

De todos modos, la relevancia práctica de las garantías normativas contenidas en las constituciones de los Länder se refuerza gracias al papel que ya la propia Ley Fundamental les otorga a partir de la mencionada cláusula de subsidiariedad en relación con el recurso en defensa de la autonomía local. ${ }^{77}$ Como consecuencia del juego del citado artículo 93.4.b) GG y de las correspondientes constituciones de los Länder, la garantía de la autonomía local puede encontrarse, pues, ante dos posibles situaciones de partida. ${ }^{78}$ Por un lado, en los Länder que cuenten con recurso jurisdiccional ante sus propios Tribunales, ${ }^{79}$ la protección se derivará esencialmente de la corres-

73 Schmidt-Aßmann y Röhl (2008): 40.

74 Burgi (2008): 75; Schmidt-Aßmann y Röhl (2008): 40; Gern (2003): 86.

75 Maurer (1995): 1040-1041. El profesor Maurer se refiere a esta tendencia en términos incluso de “condicionamiento" por parte del Tribunal Constitucional Federal a la actividad de los legisladores de los Länder a través de su jurisprudencia sobre el art. 28.2 GG.

76 Schmidt-Aßmann y Röhl (2008): 39; Kluth (2004): 657 (habla de la existencia de un contenido unitario en el Derecho constitucional de los Länder sobre la autonomía local).

77 Velasco Caballero (2010): 66.

78 Burgi (2008): 75-76.

79 Salvo error por nuestra parte, a día de hoy, solo el Land de Schleswig-Holstein no ha previsto 30 expresamente un recurso análogo al del art. 93.4 GG. 
pondiente Constitución del Land, actuando el artículo 28.2 GG y sus correspondientes principios únicamente como modelo interpretativo de mínimos. Mientras que, por el contrario, en los estados federados que no cuenten con su propio procedimiento para la defensa de la autonomía local (o cuando este solo cubra una parte de los supuestos previstos a nivel federal), los entes locales tendrán únicamente abierta la vía ante el Tribunal Constitucional Federal y, por tanto, el parámetro de enjuiciamiento lo constituirá exclusivamente el artículo 28.2 GG.

En este contexto, la doctrina alemana ha distinguido una triple función de las constituciones de los $L a ̈ n d e r$ en relación con la autonomía local. ${ }^{80}$ En primer término, todas trasladan el reconocimiento de la autonomía local previsto en la Constitución federal, desarrollando su contenido y concretando sus titulares para el ámbito territorial correspondiente. En segundo lugar, contienen, con distinto alcance, garantías adicionales a las previstas en la Ley Fundamental, especialmente en el ámbito de la autonomía financiera y en la regulación de las alteraciones territoriales de los entes locales. Finalmente, regulan también los términos en que se concreta su integración organizativa en la administración estatal (del Land).

Dejando a un lado esta última cuestión, que será tratada más adelante, seguidamente examinamos en qué se concretan estas funciones, distinguiendo, del mismo modo que hemos hecho en relación con la Constitución federal, entre los titulares y el contenido de la autonomía local.

\subsubsection{La concreción de los titulares de la autonomía local: las "agrupaciones de municipios"}

De entrada, debe constatarse que todas las constituciones realizan un reconocimiento expreso de la autonomía a los municipios y a las agrupaciones de municipios. ${ }^{81}$ Reconocimiento que, como sabemos, viene ya impuesto por la Constitución Federal. Hemos destacado ya el papel que, ante la falta de concreción del artículo 28.2 GG, pueden jugar las constituciones de los Länder en la determinación de las "agrupaciones de municipios" que, junto al Kreis, gozarán del derecho a la autonomía en cada uno de los estados federados. ${ }^{82}$ No obstante, un repaso a las correspondientes previsiones constitucionales nos pone sobre el aviso de que dicha concreción quedará, en la mayoría de los casos, en manos del respectivo legislador del Land, puesto que son escasas las ocasiones en que las normas constitucionales cumplen dicho papel.

Así, buena parte de las Landesverfassungen (Brandemburgo, Hesse, RenaniaWestfalia, Renania-Palatinado, Sarre, Schleswig-Holstein, Turingia) garantizan la au-

80 Así Kluth (2004): 656.

81 Art. 71-76 LVerfBW; Art. 10-12, 83 LVerfBay.; Art. 97-99 LVerfBbg.; Art. 137 LVerf Hess.; Art. 7275 LVerfMV; Art. 57, 58 LVerfNds.; Art. 1, 78, 79 LVerfNW; Art. 49, 50 LVerfRP; Art. 117-123 LVerfSaarl.; Art. 82.2 y 84-89 LVerfSachs.; Art. 2.3, 87-90 LVerfSAnh; Art. 2, 46-49 LVerfSH; Art. 91-95 LVerfThür.

82 Recuérdese lo dicho en el apartado 4.1.1. 
tonomía a las "agrupaciones de municipios" en general (Gemeindeverbände), sin especificar qué tipos de entidades supramunicipales cabe incluir en ellas, trasladando, por tanto, a los ordenamientos estatales la indeterminación de la Grundgesetz en esta cuestión. Solo en casos excepcionales, se explicita -recogiendo, por otra parte, lo que ya impone, como hemos visto, la interpretación mayoritaria sobre la Ley Fundamental- que la garantía constitucional de la autonomía se proyecta necesariamente sobre el Kreis, sea de forma exclusiva sin nombrar a ninguna otra agrupación municipal (Mecklemburgo-Pomerania Occidental) o incluso distinguiéndola de dicha categoría genérica (Sajonia y Sajonia-Anhalt). Mención especial merecen también los supuestos particulares en los que, además de los Kreise o de las agrupaciones de municipios en general, se amplía específicamente el conjunto de titulares de autonomía a otras entidades distintas como: "el resto de corporaciones de Derecho público" (en Baja Sajonia) o junto a ellas las mancomunidades (Zweckverbände) y los establecimientos (Anstalten) de Derecho público (en Baden-Würtemberg). Finalmente, algunas constituciones reconocen también la autonomía de agrupaciones de municipios resultantes de las propias tradiciones históricas del respectivo estado federado, como las Bezirke, de Baviera o las Landschaftsverbände en Mecklemburgo-Pomerania Occidental, si bien estas últimas se mencionan únicamente con carácter potestativo.

\subsubsection{Contenido de la autonomía local}

Más allá de la determinación de los sujetos titulares, el alcance de las constituciones de los Länder en relación con la autonomía local se proyecta especialmente en la labor de perfeccionamiento de su contenido de protección. Sin poder entrar ahora a analizar con detalle las distintas regulaciones, destacamos algunos elementos que resultan de interés especialmente por su contraste con la garantía -ya conocida- del artículo 28.2 GG.

De entrada, la mayoría de Landesverfassungen define a los municipios como "único titular de las competencias públicas en su territorio, salvo que la ley disponga lo contrario". Algunas de ellas amplían también dicha calificación a las agrupaciones de municipios, y singularmente a los Kreise. ${ }^{83}$ Unido a las dificultades existentes para delimitar el sentido de tal expresión, la doctrina alemana ha señalado la necesidad de conciliar cualquier interpretación que se haga referida a las agrupaciones municipales con la garantía del artículo 28.2 GG, recordando la prioridad constitucional que en la asignación de las competencias propias de carácter local ostentan los municipios. ${ }^{84}$

Junto al reconocimiento genérico de la autonomía, el Derecho constitucional de los Länder contiene algunas previsiones que delimitan el alcance de la protección frente al legislador, quien obviamente desarrollará estas y otras cuestiones en ejerci-

83 Así, los art. 97.2 LVerfBbg, art. 78.2 LVerfNW, 87.2 LVerfSAhn

84 Kluth (2004): 658. 
cio de su competencia sobre el régimen local. Aunque no todas las constituciones recogen todos y cada uno de los puntos siguientes, dichas previsiones pueden resumirse en regulaciones sobre:

a) Competencias locales. En términos generales, no se concretan los ámbitos materiales y/o funcionales de las competencias municipales o supramunicipales, ${ }^{85}$ sino que las regulaciones en esta cuestión se centran en los principios de asignación de competencias. Así, se admite la posibilidad de delegación de competencias por los Länder y se determinan los requisitos generales necesarios para ello. En relación con las competencias propias o autónomas, algunas constituciones establecen condiciones a la conversión legal de las competencias voluntarias en obligatorias.

b) Control sobre los entes locales. En términos de principio, suele preverse que la regla general es el control de legalidad de los estados federados sobre las competencias locales de carácter propio. En relación con las competencias delegadas, se admite el control de oportunidad mediante las instrucciones de las autoridades estatales.

c) Participación local. Buena parte de las constituciones prevén también la participación de los entes locales en los procedimientos normativos del Land que les afecten de forma directa. Allí donde está previsto, el procedimiento es siempre el de la audiencia de las organizaciones representativas de los intereses locales (Spitzenverbände). ${ }^{86}$

d) Régimen económico y financiero. Este es sin duda uno de los campos en los que las constituciones de los estados se detienen con mayor insistencia. ${ }^{87} \mathrm{La}$ diversidad de regulaciones existente puede reconducirse, en términos generales, a dos cuestiones. Primero, el reconocimiento de un derecho genérico de los municipios y agrupaciones de municipios a unos recursos financieros adecuados, que, en algunas ocasiones, viene concretado en el derecho a tener sus propias fuentes impositivas (a veces, incluso para las agrupaciones de municipios). ${ }^{88} \mathrm{Y}$, por otra parte, el establecimiento, con diferente intensidad de detalles, de principios como el de la necesaria conexión entre competencias e ingresos locales (Konnexitätsprinzip), que a su vez obliga al Land a que las transferencias de competencias que realice a los entes locales deban

85 Solo en Baviera se concreta la garantía de la autonomía del municipio a través de la enumeración de un listado abierto de materias en las que le corresponde un ámbito de competencias propio (art. 83.1 LVerfBay).

86 Arts. 97.4 LVBbg, 57.4 LVNds, 84.2 LVerfSachs, 91.4 LVerfThür.

87 No en vano el Tribunal Constitucional Federal ha señalado que la asignación financiera del Land a los entes locales es "la vertiente central de la pertenencia organizatoria de los entes locales a los $L a ̈ n d e r "$. BVerfGE $86,148,218$ y ss.

88 Arts. 79.I LVerfNW, 73.2 LVerfBW, 99, LVerfBbg, 73.1 LVerfMV, 58, LVerfMV, 49.5.II, LVerfRhPf, 119.1.II LVerfSaarl, 93.2. LVerfThür. 
ir acompañadas de la correspondiente transferencia de recursos como compensación a los costes adicionales que puedan producirse. ${ }^{89}$

e) Alteraciones territoriales. Otro de los aspectos que merecen mayor atención por las constituciones de los Länder y que, a su vez, presenta una regulación más homogénea en todas ellas es el de la determinación de los requisitos materiales y procedimentales necesarios para llevar a cabo las modificaciones territoriales de los entes locales individualmente considerados (sobre todo, municipios y Kreise). En términos generales, se exige en todo caso que tales medidas de reforma se justifiquen por razones de interés público y que cuenten con la audiencia previa de los entes locales afectados; requisitos, que, como hemos visto, ya se derivan de la jurisprudencia del Tribunal Constitucional Federal. Entre las causas que se admiten como razones justificativas de dichas alteraciones territoriales pueden señalarse el refuerzo de la capacidad de gestión de las entidades locales, la homogeneización en las condiciones de vida y del medio ambiente, la disminución de los desequilibrios territoriales, la mejora en la economía y eficiencia de la administración local o la proximidad al ciudadano, entre otras. ${ }^{\circ}$ En cualquier caso, la alusión a la concurrencia de motivos de interés general refleja un margen de discrecionalidad del legislador, que, en todo caso, se somete al correspondiente control jurisdiccional.

En este contexto, la nueva ola de reformas territoriales que algunos Länder han emprendido sobre el nivel supramunicipal, y especialmente sobre el Kreis, ha dado lugar a un relevante pronunciamiento jurisprudencial, de repercusión en toda la Federación y que ha llegado a erigirse en el marco a tener en cuenta para futuras reformas de este tipo "incluso en el resto de Länder". ${ }^{11} \mathrm{La}$

89 Arts. 78.3 LVerfNW, 71.3 LVerfBW, 97.3 LVerfBbg, 137.4 y 5 LVerfHess, 72.3 LVerfMV, 85.2 LVerfSachs, 87.3 LVerfSAnh, 49.2 LVerfSH, 93.1 LVerfThür. Al respecto merece ser destacada la jurisprudencia que los Tribunales Constitucionales de los Länder han desarrollado en los últimos años. Véase SchmidtAßmann y Röhl (2008): 39-40. Una exhaustiva panorámica general, con una sistematización y clasificación de los diferentes modelos constitucionales regulatorios de las garantías financieras en Henneke, H-G. (2003), "Landverfassungsrechtliche Finanzgarantien der Kommunen zwischen normativen Neuregelungen und verfassngsgerichtlicher Ausformung”, Der Landkreis, 2-3: 190 y ss.

90 Kluth (2004): 660-661.

91 La cantidad de comentarios y estudios doctrinales aparecidos al respecto confirma la relevancia de dicha sentencia más allá del Land de Mecklemburgo-Pomerania Occidental. Entre otros, Meyer, Hubert (2007), "Lehrstück über Demokratie in überschaubaren kommunalen Strukturen - MVVerfG kippt RegionaIkreise”, Neue Zeitschrift für Verwaltungsrecht, 9: 1024 y ss; Meyer, Hans (2008), “Liegt die Zukunft Mecklenburg-Vorpommerns im 19. Jahrhundert? - Zum Neugliederungsurteil des Landesverfassungsgerichts",Neue Zeitschrift für Verwaltungsrecht, 1: 24 y ss.; Henneke, H.G. (2007), “Bürgerschaftliche-Dimension kommunaler Selbstverwaltung gebietet überschaubere Landkreise”, Der Landkreis, 8-9: 10-15; Kluth, W. (2008), “Der grundgesetzliche Schutz der Landkreise vor Aufgabenübertragung und Aufgabenentzug: Zugleich eine Besprechung des Urteils des Bundesverfassungsgerichts vom 20. Dezember 2007”, ZG: Zeitschrift für Gesetzgebung, 3: 292-303. Stüer, B. (2007), "Verwaltungsreform auf Kreisebene - Effektivitätsgewinn nur bei bürgerschaftlichem Engagement”, Deutsches Verwaltungsblatt, 20: 1267-1274; y la obra colectiva Büchner, C. et al. (2008), Verfassungsrechtliche Anforderungen an Kreisgebietsreformen. Potsdam: Verlag Universi-
tät Potsdam. 
sentencia del Tribunal Constitucional del Land de Mecklemburgo-Pomerania Occidental, de 26 de julio de $2007^{92}$ declaró inconstitucional la Ley, de 23 de mayo de 2006, de modernización de la administración de dicho estado, que pretendía sustituir los doce Kreise existentes por cinco de mayor tamaño, en los que también se integraban las hasta entonces existentes seis ciudades libres de Kreis. Sin poder entrar aquí en mayores precisiones, sí reviste interés destacar que el argumento principal de la sentencia para poner freno a dicha reforma reside en la vulneración del elemento político-democrático de la autonomía local (bürgerschaftlich-demokratisches Element). El Tribunal afirma que la reforma territorial aprobada no valoró suficientemente la afectación al principio democrático y que, en este caso, la anteposición de consideraciones de eficacia o racionalización administrativa conducía a un resultado incompatible con la legitimación democrática garantizada constitucionalmente a los Kreise.

\section{LOS ENTES LOCALES COMO PARTE DE LA ORGANIZACIÓN DE LOS LÄNDER}

El último de los elementos que, junto a su naturaleza democrática y autónoma, caracterizan la integración de los entes locales en la estructura federal del Estado alemán es su consideración como parte de la organización institucional de los Länder. Dicho de otro modo, los entes locales son efectivamente entidades democráticas y autónomas sobre las que se constituye el Estado federal, pero a su vez no pueden sino calificarse como parte integrante de la organización de los distintos estados federados. Analizamos a continuación en qué se traduce tal afirmación.

\subsection{Los entes locales no son un "tercer pilar" del Estado federal}

Desde el punto de vista de la distribución vertical (u organización territorial) del poder público, en Alemania los entes locales forman parte del ámbito de organización de los Länder. ${ }^{93}$ De acuerdo con la Ley Fundamental, Alemania se constituye en un Estado federal (Bundesstaatsprinzip), en el que el carácter estatal (Staatlichkeit) solo está atribuido a la Federación y los Länder. ${ }^{94}$ En este contexto, la integración de los entes locales en el conjunto del Estado, y con ella su ejercicio del poder público estatal, solo puede comprenderse, de acuerdo con la Ley Fundamental, a partir de su inserción institucional en la organización de los Länder.

92 (LVerfG 9/06-17/06).

93 Schmidt-Aßmann y Röhl (2008): 21-22; Burgi (2008): 12; Pielow (1993): 216-217; Dreier (2006): 469. Isensee, J. (1991), "Idee und Gestalt des Föderalismus im Grundgesetz", en Isensee y Kirchhof (dirs.), Handbuch des Staatsrechts der Bundesrepublik Deutschland, Vol. 4. Heidelberg: Müller, p. 610 y ss.; Schoch, F. y Wieland, J. (1995), Finanzierungsverantwortung für gesetzgeberisch veranlaßte kommunale Aufgaben. Baden-Baden: Nomos, p.53; Carro (2006): 232. También la jurisprudencia ha reconocido esta integración de los entes locales en los Länder, véase BVerfGE, 39, 96, 109; 86, 148, 125.

94 Por todos, Isensee (1991): 526 y ss. 
A esta conclusión llega la doctrina alemana a través de la interpretación de varios elementos constitucionales: de entrada, se parte, como ya hemos visto, de la inclusión del artículo 28.2 (autonomía local) en el título II de la Ley Fundamental dedicado a "la Federación y los Länder"; en segundo término, se afirma que a través de dicha integración se dota de sentido la previsión del artículo 28.3 GG, según la cual la Federación debe garantizar que el orden constitucional de los Länder respete la autonomía local; por último, se llega también a la misma conclusión a partir del artículo 106. 9 GG, que dispone que "se considerarán como ingresos y gastos de los Länder también los ingresos y gastos de los municipios (y agrupaciones de municipios)". 95

No cabe, por tanto, en la Ley Fundamental la concepción alternativa, según la cual los entes locales constituyen "un tercer pilar" del Estado federal, junto a la Federación y los Länder, tal y como defendieron en el pasado algunos planteamientos de alto contenido político. ${ }^{96}$ No obstante, parte de la doctrina actual describe la posición jurídica de los entes locales en el conjunto de la organización estatal refiriéndose a ella como un "tercer pilar debilitado"97 o un "Staat light", ${ }^{98}$ con la finalidad de poner de relieve que, a pesar de la intensa vinculación que mantienen con los estados federados, la protección constitucional de la autonomía local sitúa a municipios y agrupaciones municipales en un espacio particular dentro del conjunto de la estructura federal, de tal manera que la distingue del resto corporaciones y de sujetos administrativos dotados de autonomía. En un sentido similar, otros autores ponen de relieve que dicha integración de los entes locales en la estructura organizativa de los estados federados lo es sin perjuicio de su existencia como un tercer nivel de carácter administrativo. ${ }^{99}$

En cualquier caso, más allá de la categorización o no de los entes locales como un tercer pilar en el conjunto de la estructura federal, lo que debe ponerse de relieve son los concretos efectos jurídicos que la integración de la estrecha vinculación jurídica entre Länder y entes locales comporta para la configuración de estos últimos. De entrada, esto se traduce en que, en los términos definidos por las propias reglas de

95 Todos o parte de estos argumentos en Burgi (2008): 12; Bovenschulte (2000): 544.

96 Así lo entienden Dreier (2006): 469; Bovenschulte (2000): 545 Entre las opciones alternativas defendidas en el pasado, pueden destacarse: 1) la creación de una "tercera cámara" a nivel federal con representación para los entes locales; 2) la creación de una „comisión local”, como reformulación de la propuesta anterior. Sobre ambas propuestas, véanse las citas doctrinales tanto de Dreier como de Bovenschulte. Además también sobre ello, Faber, H. (2002), “Art. 281 II y 2", en Alternativkommentar GG.

97 Thieme, W. (2007), "Die Gliederung der deutschen Verwaltung“, en Mann, T. y Püttner, G. (dirs.), Handbuch der kommunalen Wissenchaft und Praxis, Berlín: Springer, p. 147-168. También se hacen eco de esta consideración, Schmidt-Aßmann y Röhl (2008): 22.

98 Burgi (2008): 12.

99 Dreier (2006): 649-650; Maurer (1995): 1040. Particularmente clarificadoras son las explicaciones de este último autor cuando expone que mientras el Estado federal se constituye entorno a dos niveles de "estatalidad", pueden distinguirse tres (o incluso cuatro) niveles administrativos (en referencia a los municipios y los Kreise). También en este sentido, Henneke, H-G. (2006), "Die Kommunen in der Föderalismusreform", en Deutsches Verwaltungsblatt, 14: 867. 
distribución de competencias entre Federación y Länder, serán estos últimos quienes ostenten la competencia exclusiva sobre el Derecho local. En segundo término, la vinculación entre Länder y entes locales se produce también en el ámbito de la organización administrativa, de tal manera que los entes locales suelen calificarse como “administración indirecta" de aquéllos. Veamos con más detalle el alcance de cada uno de estos aspectos.

\subsection{La competencia exclusiva de los Länder en materia de Derecho local}

De acuerdo con el reparto de competencias entre la Federación y los Länder establecido en la Ley Fundamental, el Derecho local (Kommunalrecht) es competencia exclusiva de los Länder, lo que incluye tanto las facultades legislativas como de ejecución en dicha materia.

Como no se trata de una materia atribuida expresamente a la Federación, ni en concepto de exclusiva (arts. 71 y 73 GG), ni en concepto de concurrente (arts. 72 y 74 GG), ${ }^{100}$ cabe concluir que, de acuerdo con la cláusula general de atribución del art. 70.1. GG (y la declaración general del art. 30 GG), los Länder ostentan la competencia legislativa exclusiva en materia de Derecho local. ${ }^{101}$ En virtud de esta competencia, los estados federados han aprobado sus propias leyes en materia de régimen local. Leyes que, por regla general, no responden a una codificación unitaria y sistemática, sino que se extienden a un conjunto de materias diversas relativas al Derecho local. Lo habitual es, pues, encontrar que los estados federados han aprobado leyes diferentes para regular: los municipios (Gemeindeordnungen), los Kreise ([Land-]Kreiseordnungen), la cooperación local (Gesetze über kommunale Zusammenarbeit o Gemeinschaftsarbeit), los tributos locales (Kommunalabgabegesetze), así como el régimen electoral local (Kommunalwahlgesetze). Solo excepcionalmente, algunos estados han regulado conjuntamente las instituciones de los municipios y los Kreise (Brandemburgo, Mecklemburgo-Pomerania Occidental, Sarre y Turingia). ${ }^{102}$ Adicionalmente, se han aprobado leyes que tienen por objeto la regulación de entidades locales específicas del correspondiente Land (p. ej., los Ämter en Schleswig-Holstein, o los Bezirke en Baviera).

En este contexto, el papel de la Federación en relación con el régimen local queda ciertamente muy limitado. Del reparto constitucional de competencias se deduce,

100 Téngase en cuenta que, tras la reforma constitucional de 2006, se ha eliminado la referencia a la legislación marco, antes contenida en el art. 75 GG (hoy derogado).

101 Burgi (2008): 5. El art. 30 GG establece que "El ejercicio de las competencias estatales y el cumplimiento de las funciones estatales competen a los Länder siempre que la presente Ley Fundamental no disponga o admita una disposición en contrario". Concretando esta declaración general para el ámbito de las competencias legislativas, el art. 70.1 GG dispone: “Los Länder poseen el derecho de legislar en tanto la presente Ley Fundamental no lo confiera a la Federación”.

102 En el caso de Mecklemburgo-Pomerania Occidental, dicha codificación (Kommunalverfassung) incluye también los preceptos relativos a la cooperación local. 
por un lado, que el Derecho local es en su esencia Derecho del Land (Landesrecht), ${ }^{103}$ y que, por tanto, la Federación no podrá aprobar leyes en dicha materia. Lo que, por otra parte, no es sino consecuencia de la integración institucional de los entes locales en la propia organización de los Länder e implica que la relación de la Federación con los entes locales deberá vehicularse necesariamente a través de aquéllos.

Esta conclusión ha sido confirmada -e incluso reforzada- por la reciente reforma constitucional de 2006 (Föderalismusreform I). ${ }^{104}$ Hasta el 1 de septiembre de 2006, fecha de entrada en vigor de dicha reforma, la Federación podía incidir sobre el Derecho Local cuando se daban las condiciones previstas en el anterior art. 84.1 GG, que disponía que, en el caso de leyes federales relativas a materias de competencia de la Federación pero ejecutadas por los Länder como asunto propio, estos podían regular las cuestiones de "organización y procedimiento" de dicha ejecución, siempre que las leyes federales, con el consentimiento del Bundesrat, no estableciesen otra cosa. En la medida en que se entendía que dentro de la "organización" se incluían las autoridades dentro de los Länder, la Federación venía autorizada a atribuir por ley competencias directamente a los entes locales, como de hecho sucedía con cierta asiduidad. En efecto, a pesar de que dicha posibilidad estaba dispuesta constitucionalmente como excepción, en la práctica, la Federación venía haciendo abundante uso de ella. ${ }^{105}$

Más allá de que la propia relación directa entre Federación y entes locales suponía un cierto atentado a las facultades organizatorias de los Länder y una anomalía en el sistema federal organizado en torno a dos niveles estatales, el problema práctico principal residía especialmente en las cargas financieras que dicha transferencia de competencias comportaba para los entes locales destinatarios de la transferencia, provocando una restricción de su autonomía financiera, también protegida constitucionalmente. ${ }^{106}$

Para resolver estos problemas, la reforma constitucional de 2006 modificó el citado artículo 84.1 GG (relativo a la ejecución de las leyes federales por los Länder

103 Schmidt-Aßmann y Röhl (2008): 17.

104 Sobre la reforma constitucional en general, pretendida como la "madre de todas las reformas", puede verse, entre otros, Meyer, Hans (2008b), Die Föderalismusreform: Konzeption, Kommentar und Kritik. Berlín: Duncker und Humblot. Entre nosotros, Arroyo Gil, A. (2009), La reforma constitucional del federalismo alemán. Estudio crítico de la 52. ${ }^{a}$ Ley de modificación de la ley fundamental de Bonn, de 28 de agosto de 2006. Barcelona: Institut d’Estudis Autonòmics, 2009. Desde una perspectiva local, Henneke, H-G.,dir., (2008), Kommunen in den Föderalismusreformen I und II. Stuttgart et al.: Boorberg Verlag. La crónica de las jornadas que dan origen a esta obra colectiva, en Ruge, K. (2008), “Die Kommunen in den Föderalismusreformen I und II", Deutsches Verwaltungsblatt, 15: 967-970.

105 Así, por ejemplo a través del establecimiento por ley de los municipios como titulares de la planificación urbanística (BVerfGE 77, 288, 299 y ss.) o de los municipios libres de Kreis y los Kreise como encargados de la ayuda social prevista en el anterior Sozialgesetzbuch XII. Estos y otros ejemplos en Burgi (2008): 6 .

106 Arroyo Gil (2009): 113-114; Försteling, W. (2007): “Das Aufgabenübertragungsverbot nach Art. 84 Abs.1 Satz 7 GG”, Der Landkreis, 2: 56-58; y entre otros muchos trabajos suyos, en sintonía con su habitual preocupación por la autonomía (financiera) de los Kreise, Henneke (2006): 867-871. 
como asunto propio), así como el 85.1 GG (relativo a la ejecución de las leyes federales por los Länder por encargo de la Federación), introduciendo -en cuanto a lo que aquí interesa- ${ }^{107}$ una frase de idéntico contenido en ambos preceptos que establece que: "No pueden transferirse competencias a los municipios ni a las agrupaciones de municipios mediante leyes de la Federación”. Por su parte, el art. 125a.1 GG dispone la vigencia de las transferencias ya existentes en la fecha de la entrada en vigor de la reforma constitucional. ${ }^{108}$

Con esta modificación, queda prohibida, pues, constitucionalmente, la transferencia y delegación de competencias a los entes locales directamente por ley federal (Bundesdurchgriff). Y, por tanto, solo los Länder podrán atribuir competencias a los entes locales. En este sentido, parece claro que se refuerza el ámbito de poder organizativo de los Länder, así como la autonomía local. Sin embargo, la doctrina alemana se ha apresurado a matizar que, para que dicha reforma constitucional surta el efecto esperado respecto a la autonomía local, deberían tenerse en cuenta algunas consideraciones. De entrada, se señala la necesaria aplicación efectiva del principio de conexión entre ingresos y gastos locales previsto por las constituciones de los Länder, de tal manera que la transferencia de nuevas competencias que puedan realizar los estados a los entes locales lleve asociada la de los recursos financieros necesarios para hacer frente a las cargas económicas que se deriven de aquellas. ${ }^{109}$ Además, se pone en duda la efectividad de la reforma en la medida en que siguen vigentes las competencias transferidas y la redacción del art. 125a.1 GG pueda amparar una ampliación de las cargas financieras mediante la modificación de las leyes federales ya existentes. ${ }^{110}$

\subsection{Los entes locales y la administración del Land. Su calificación como "administración indirecta"}

En Alemania los entes locales se definen tradicionalmente como "administración indirecta del Land"' (mittelbare Staatsverwaltung der Länder). Aunque no se trata de un concepto de Derecho positivo (ni la Ley Fundamental ni las legislaciones de régimen local lo recogen expresamente), las exposiciones dogmáticas al uso sobre el Derecho de la organización administrativa alemana distinguen habi-

107 El art. 84.1 GG fue objeto de más modificaciones. P. ej. se eliminó la necesidad del consentimiento del Bundesrat para que la Federación pudiese regular la organización y el procedimiento en los supuestos de ejecución previstos por dicho artículo, si bien esto fue compensado con la posibilidad de que los Länder puedan aprobar legislación divergente a la de la Federación.

108 125a 1: "El Derecho que haya sido aprobado como Derecho federal, pero que debido a la reforma del artículo 74, apartado 1, de la inclusión del artículo 84, apartado 1, frase 7, del artículo 85, apartado 1, frase 2 o del artículo105 a, apartado 2 a, frase 2 o a causa de la derogación del artículo 74 a, 75 o 98, apartado 3, frase 2, no pudiera ser aprobado como Derecho federal sigue vigente como Derecho federal. Puede ser sustituido por el Derecho de los Länder."

109 Burgi (2008): 12. Henneke (2006): 867-871.

110 Burgi (2008): 12; Schoch, F. (2007), “Verfassungswidrigkeit des bundesgesetzlichen Durchgriffs auf Kommunen", Deutsches Verwaltungsblatt, 5: 261-269. 
tualmente entre administración estatal directa (unmittelbare Staatsverwaltung) y administración estatal indirecta (mittelbare Staatsverwaltung), según si las tareas estatales (de la Federación o de los Länder) son ejercidas por sus respectivos órganos y autoridades (Behörden) o bien por entes administrativos dotados de personalidad jurídica pública propia, a saber, Corporaciones (Körperschaften), Establecimientos (Anstalten) y Fundaciones (Stiftungen) de Derecho público. ${ }^{111}$ Así, mientras en el caso de la administración estatal directa se habla de la existencia de un poder originario estatal, en la administración indirecta los sujetos administrativos ejercen el poder público derivado o indirecto. Pues bien, es en el marco de esta distinción cuando suele calificarse a los entes locales como parte de la administración indirecta estatal (de los Länder). Municipios y agrupaciones de municipios tienen -como ya se ha dicho- carácter de corporaciones de Derecho público, son resultado de la descentralización estatal y, como tales, ejercen el poder público estatal derivado. ${ }^{112}$

En cualquier caso, la incorporación de las entidades locales a esta categoría de "administración estatal indirecta" es frecuentemente objeto de matices importantes, que ayudan a su correcta comprensión e incluso a una cierta relativización de sus efectos prácticos. Así, en la mayoría de casos, tal calificación se acompaña de la concepción de los entes locales (especialmente, municipios y Kreise) como un caso muy particular de entre las Corporaciones, puesto que, a diferencia del resto de personas jurídicas que se incluyen en esta categoría, gozan de legitimidad democrática directa y de conformidad con la garantía constitucional de su autonomía, están dotadas de un amplio ámbito de competencias propias y de potestad territorial. ${ }^{113}$ Frente a esta posición, presidida por una manifiesta voluntad de sistematización y claridad, otros autores prefieren utilizar un concepto más restringido de "administración estatal indirecta” y excluyen de ella a los entes locales, al entender incompatible dicha categoría con las características propias de la autonomía local. ${ }^{114}$

Más allá de estas consideraciones, conviene destacar ahora que, en el marco de la organización administrativa de los Länder, los entes locales se hallan vinculados estrechamente a la administración directa de estos y, en concreto, a su llamado nivel inferior (Unterstufe). ${ }^{115}$ Los términos y particularidades de dicha vinculación vienen

111 Maurer (2009): 522 y ss.; Burgi, M. (2006), “Verwaltungsorganisationsrecht”, en Erichsen y

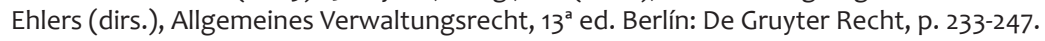

112 Burgi (2008): 12-13. Véase el apartado 2.

113 Maurer (2009): 523.

114 Con ello -se dice- se mezclan inadmisiblemente diversas categorías jurídicas, puesto que también la Federación y los estados federados son corporaciones territoriales dotadas de legitimidad democrática. Kluth (2004): 327.

115 Tradicionalmente la administración de los Flächenländer se organiza en torno a tres niveles: superior, medio e inferior. El nivel superior (Oberstufe) está compuesto por las autoridades superiores del Land (el gobierno del Land, el ministro presidente, los ministros así como las autoridades superiores nombradas directamente por un ministro), cuyas competencias se extienden al conjunto del territorio del Land. El nivel intermedio (Mittelstufe) lo compone, además de las autoridades especiales, el Regierungsbezirk
(Regierungspräsidium en Baden-Würtemberg y Hesse, Bezirksregierung en Renania-Westfalia o Regierung 
regulados en las correspondientes constituciones y, especialmente, en las leyes de organización administrativa de los propios Länder. Con carácter general, las principales manifestaciones de esta estrecha relación se producen en dos ámbitos distintos, respecto a la atribución de competencias, de un lado, y al ejercicio de la tutela sobre los entes locales, de otro. ${ }^{116}$

De entrada, los entes locales ejercen competencias en calidad de administración estatal inferior (als untere staatliche Verwaltungsbehörde). Se trata, pues, de competencias que se añaden, con diferentes plasmaciones según las diferentes legislaciones de los Länder, a las de carácter propiamente local (derivadas de su autonomía) y que provienen de la delegación o encomienda por parte de los propios estados federados. Paralelamente, los entes locales quedan sometidos al control permanente de las autoridades estatales (Kommunalaufsicht), si bien con diferente alcance según los supuestos. En términos generales, cabe hablar de un control de legalidad ante las competencias propias locales, control que se extiende al ámbito de la oportunidad en el caso de competencias delegadas, a través de múltiples medios (solicitud de información, derecho de veto, ordenación y dirección, nombramiento de comisionados o incluso excepcionalmente la sustitución o subrogración).

No podemos concluir estas consideraciones sobre las relaciones entre el nivel estatal y el local en cuanto al cumplimiento de funciones sin hacer referencia -aunque sea breve- a la especial posición del Kreis en la estructura federal alemana. En el ámbito territorial del Kreis, el Landrat (consejero estatal) es a la vez órgano de la administración estatal en su nivel inferior y órgano del ente local supramunicipal. En efecto, a través de esta figura se pone de relieve una de las mayores peculiaridades del gobierno local supramunicipal en Alemania: la confluencia de la administración estatal y la local en un mismo órgano unipersonal. Confluencia que se hace posible a través de la institución jurídica del llamado "préstamo de órganos" (Organleihe). En términos generales, el Kreis "presta" su órgano (Landrat) a la administración del Land de tal modo que se somete a las instrucciones de ésta como si fuera órgano de la misma, imputándose sus decisiones directamente al estado federado.

en Baviera), que tiene una función de mediación y coordinación entre las autoridades del nivel superior e inferior en cada una de las demarcaciones territoriales determinadas. Finalmente, existe un nivel inferior de administración (Unterstufe), que se concreta sobre todo en la actuación del Landrat, como autoridad estatal en el territorio de un Kreis. Las ciudades libres de Kreis asumen también dicha función en el territorio de su municipio.

No obstante, hay que tener en cuenta que, con el paso del tiempo y en el marco de diversas reformas administrativas, un buen número de Länder (Brandemburgo, Mecklemburgo-Pomerania Occidental, Schleswig-Holstein, Sarre, Baja Sajonia) ha renunciado a la instancia intermedia y ha configurado su administración general en torno a dos únicos niveles (superior e inferior). En algunos casos, se ha sustituido dichas autoridades intermedias por otras estructuras más simplificadas (Renania-Palatinado, Sajonia, Turingia). Las diferencias entre Länder se dan también en cuanto a las denominaciones: mientras en el norte se utiliza el criterio personal (Regierungspräsident o Landrat), en el sur las denominaciones atienden al conjunto de la estructura organizativa (Regierungsrpäsidium o Landratsamt). Sobre esto, entre otros, Mau$\operatorname{rer}$ (2009): 554-556.

116 Burgi (2008): 18-19. 


\section{CONSIDERACIONES FINALES. LA POSICIÓN DE LOS ENTES LOCALES EN UN MARCO FEDERAL: POTENCIALIDADES Y LÍMITES}

Llegados a este punto y expuesto el estado de la cuestión en cuanto a la posición jurídico-institucional del gobierno local en el conjunto del Estado federal alemán, concluimos con una breve reflexión de conjunto. En este contexto, podemos afirmar que el marco constitucional descrito cumple una importante doble funcionalidad en cuanto a la posterior configuración legal del gobierno local en Alemania. Por un lado, la posición constitucional del nivel local en la Constitución federal abre la puerta a que los Länder diseñen modelos de gobierno y administración local de forma diversa y diferenciada. Pero, del mismo modo, tal marco constitucional impone unos límites infranqueables que deberán respetarse en el conjunto de la Federación.

La distribución territorial del poder público en el Estado federal alemán sitúa, en efecto, a los entes locales en una posición tal que su configuración jurídica queda sometida a la competencia exclusiva de los Länder, excluyéndose cualquier posibilidad de relación directa con la Federación. Dicha interiorización de los entes locales en los Länder es, pues, el punto de partida a la diversidad normativa en materia local.

Es cierto que dicha diversidad puede conducir a una heterogeneidad y una complejidad normativas que dificulten la identificación y la comprensión de un eventual sistema general de gobierno local, especialmente al observador acostumbrado a tratar con un régimen legislativo unitario y homogéneo. ${ }^{117}$ Como también lo son las más que probables dificultades de articulación práctica entre los diferentes "subsistemas" locales de los diferentes Länder. Sin embargo, es posible admitir que tal punto de partida tiene también sus ventajas. Por un lado, permite a cada Land adaptar su modelo de organización local a sus propias peculiaridades geográficas, económicas y político-sociales. Por otro, la concurrencia entre las diferentes políticas en materia de autonomía local puede fomentar la mejora de cada una de ellas, en una especie de "federalismo competitivo" (Wettbewerbsföderliasmus) a nivel local. ${ }^{118}$

En cualquier caso, la diversidad en relación con el Derecho local derivada de la configuración federal del Estado tiene, como hemos visto a lo largo de este trabajo, importantes límites en la Constitución federal, que garantiza el principio democrático y el de autonomía local. Estos dos principios se erigen en elementos fundamentales para la configuración del gobierno local a la vez que dotan de estabilidad al conjunto

117 Un reciente e indispensable intento por describir y analizar jurídicamente el modelo de gobierno local en los estados descentralizados y en particular en Alemania, es el que constituye la obra colectiva dirigida por Velasco Caballero, F., (2010).

118 Pielow, C. (2000), “Las estructuras del gobierno local en un marco federal: la asimetría y las singularidades", en Font Llovet, T., dir., Anuario del Gobierno Local 1999/2000. Madrid-Barcelona: Marcial Pons- Diputació de Barcelona - IDP, p. 103-104. 
de la estructura federal, en la medida en que deben trasladarse a cada uno de los sistemas diseñados por los Länder.

Buen ejemplo del grado de intensidad del que siguen gozando en Alemania la garantía constitucional de la democracia y de la autonomía locales, así como de la estrecha vinculación que existe entre ambas, la ofrece, como también hemos apuntado aquí, la anulación por los tribunales de la reforma territorial aprobada en el Land de Mecklemburgo-Pomerania Occidental que -en el marco de una fuerte política de racionalización administrativa- propuso reducir drásticamente su número de Kreise. El límite queda claro. Tales medidas no son compatibles con los principios del Estado federal constitucional, que se sustenta en la construcción de una "democracia desde abajo hacia arriba".

\section{REFERENCIAS BIBLIOGRÁFICAS}

AAVV. (2007), Autonomía Municipal. Administración y Regulación Económica. Títulos Académicos y Profesionales. Actas del II Congreso de la Asociación de Profesores de Derecho Administrativo. Pamplona: Thomson-Aranzadi - AEPDA

Arroyo Gil, A. (2009), La reforma constitucional del federalismo alemán. Estudio crítico de la 52. '. Ley de modificación de la ley fundamental de Bonn, de 28 de agosto de 2006. Barcelona: Institut d'Estudis Autonòmics, 2009.

Bovenschulte, A. (2000), Gemeindeverbände als Organisationsformen kommunaler Selbstverwaltung. Baden-Baden: Nomos.

Büchner, C. et al. (2008), Verfassungsrechtliche Anforderungen an Kreisgebietsreformen. Potsdam: Verlag Universität Potsdam.

Bull, H.P. (2008), “Kommunale Selbstverwaltung heute - Idee, Ideologie und Wirklichkeit”, Deutsches Verwaltungsblatt, 1: 1-11.

Burgi, M. (2006), "Verwaltungsorganisationsrecht", en Erichsen y Ehlers (dirs.), Allgemeines Verwaltungsrecht, $13^{\mathrm{a}}$ ed. Berlín: De Gruyter Recht.

Burgi, M. (2008), Kommunalrecht, $2^{\mathrm{a}}$ ed. Múnich: $\mathrm{CH}$ Beck.

Burmeister, J. (1977), Verfassungstheoretische Neukonzeption der kommunalen SeIbstverwaltung. Múnich: Vahlen.

Carro Fernández-Valmayor, J. L. (2006), “El régimen local alemán: una introducción”, en Font Llovet, T. (dir.), Anuario del Gobierno Local 2005. Barcelona: Fundación Democracia y Gobierno Local - IDP.

Dreier, H. (2006), “Art. 28”, en Dreier, H. (dir.), Grundgesetz Kommentar, Vol. II, $2^{\mathrm{a}}$ ed. Tübingen: Mohr Siebeck.

Embid Irujo, A. (1980), “Autonomía local y Constitución: aproximación al concepto y significado de la declaración constitucional de autonomía municipal”, Revista Española de Derecho Administrativo, 30: 437-470.

Esteve Pardo, J. (1991), Organización supramunicipal y sistema de articulación autonómica y orden local. La experiencia de la RFA. Bases y perspectivas en España. Barcelona: Civitas -Diputació de Barcelona.

Faber, H. (2002), “Art. 281 II y 2”, en Alternativkommentar GG. 
Faber, H. (2008), “Erwiderung auf den Beitrag von Henneke und Ritgen zum 250. Geburtstag des Freiherrn vom Stein und zu seiner Bedeutung für die kommunale Selbstverwaltung", Deutsches Verwaltungsblatt, 7: 437 y ss.

Försteling, W. (2007): "Das Aufgabenübertragungsverbot nach Art. 84 Abs.1 Satz 7 GG”, Der Landkreis, 2: 56-58.

García Roca, J. (1985), “La autonomía del Derecho político municipal. Fundamentos dogmáticos de la Constitución Española”, en AAVV, Organización territorial del Estado. Madrid: Instituto de Estudios Fiscales.

García Morillo, J. (1998), La garantía constitucional de la autonomía local. Madrid: Marcial Pons - Diputación de Barcelona.

Gern, A. (2003), Deutsches Kommunalrecht, $3^{\text {a }}$ ed. Baden-Baden: Nomos.

Gönnenwein, O. (1967), Derecho municipal alemán. Madrid: IEAL.

Gracia Retortillo, R. (2010), "El nivel supramunicipal de gobierno local en Alemania”, Revista d'estudis autonòmics i federals, 11: 83-141.

Henneke, H-G. (2003), “Landverfassungsrechtliche Finanzgarantien der Kommunen zwischen normativen Neuregelungen und verfassngsgerichtlicher Ausformung", Der Landkreis, 2-3: 190 y ss.

Henneke, H-G. (2006), “Die Kommunen in der Föderalismusreform”, en Deutsches Verwaltungsblatt, 14: 867-871.

Henneke, H.G. (2007), “Bürgerschaftliche-Dimension kommunaler Selbstverwaltung gebietet überschaubere Landkreise”, Der Landkreis, 8-9: 10-15.

Henneke, H-G. y Ritgen, K. (2007), “Aktivierung bürgerschaftlicher Selbst-Verwaltung in Städten, Kreisen und Gemeinden - zur Bedeutung der Lehren des Freiherrn vom Stein für die kommunale Selbstverwaltung der Gegenwart", Deutsches Verwaltungsblatt, 20: 1253-1266.

Henneke, H-G.,dir., (2008), Kommunen in den Föderalismusreformen I und II. Stuttgart et al.: Boorberg Verlag.

Isensee, J. (1991), "Idee und Gestalt des Föderalismus im Grundgesetz", en Isensee y Kirchhof (dirs.), Handbuch des Staatsrechts der Bundesrepublik Deutschland, Vol. 4. Heidelberg: Müller.

Kluth, W. (2004), "Die kommunale Selbstverwaltung", en Wolff, H. et al., Verwal-

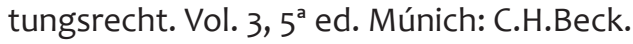

Kluth, W. (2008), “Der grundgesetzliche Schutz der Landkreise vor Aufgabenübertragung und Aufgabenentzug: Zugleich eine Besprechung des Urteils des Bundesverfassungsgerichts vom 20. Dezember 2007", ZG: Zeitschrift für Gesetzgebung, 3: 292-303.

Maurer, H. (1995), "Verfassungsrechtliche Grundlagen der kommunalen Selbstverwaltung", Deutsches Verwaltungsblatt, 19: p.1037-1046

Maurer, H.(2009), Allgemeines Verwaltungsrecht, 17a ed. Múnich: CH Beck.

Mempel, M. (2007), "Von der Stein-Zeit ins 21. Jahundert - Kommunale Selbstverwaltung in Zeiten des demografischen Wandels", Der Landkreis (12): 607 y ss.

Meyer, Hans (2008a), “Liegt die Zukunft Mecklenburg-Vorpommerns im 19. Jahrhundert? - Zum Neugliederungsurteil des Landesverfassungsgerichts",Neue Zeits-

44 chrift für Verwaltungsrecht, 1: 24 y ss. 
Meyer, Hans (2008b), Die Föderalismusreform: Konzeption, Kommentar und Kritik. Berlín: Duncker und Humblot.

Meyer, Hubert (2007), “Lehrstück über Demokratie in überschaubaren kommunalen Strukturen - MVVerfG kippt Regionalkreise”, Neue Zeitschrift für Verwaltungsrecht, 9: 1024 y ss.

Oebbecke, J. (1984), Gemeindeverbandsrecht Renania-Westfalia. Eine systematische Darstellung. Münster: Deutscher Gemeindeverlag - W. Kohlhammer.

Parejo Alfonso, L. (1981), Garantía institucional y autonomías locales. Madrid: IEAL.

Pielow, C. (1993), Autonomía Local in Spanien und kommunale Selbstverwaltung in Deutschland. Múnich: Franz Vahlen.

Pielow, C. (2000), "Las estructuras del gobierno local en un marco federal: la asimetría y las singularidades", en Font Llovet, T., (dir.), Anuario del Gobierno Local 1999/2000. Madrid-Barcelona: Marcial Pons- Diputació de Barcelona - IDP.

Pieroth, H.D. (2006), “Art. 28”, en Jarass, B. y Pieroth, H.D. (dirs.), GG: Grundgesetz für die Bundesrepublik Deutschland. Kommentar, $8^{\text {a }}$ ed. Múnich: $\mathrm{CH}$ Beck.

Ruge, K. (2008), “Die Kommunen in den Föderalismusreformen I und II”, Deutsches Verwaltungsblatt, 15: 967-970.

Schmidt-Aßmann, E. y Röhl, H.C. (2008), “Kommunalrecht”, en Schmidt-Aßmann, E. y

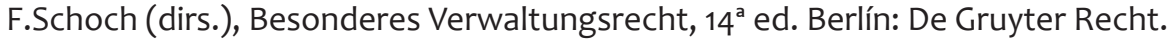
Schmitt, C. (1973), Verfassungsrechtliche Aufsätze. Berlín: Duncker-Humblot.

Schoch, F. (1993), “En relación a la situación de la autonomía local tras la „SentenciaRastede“ del Tribunal Constitucional Federal”, Documentación administrativa, 234 (Ejemplar dedicado a: El Derecho administrativo en Alemania: Tendencias actuales I): 281-321.

Schoch, F. (2001), "Der verfassungsrechtliche Schutz der kommunalen Selbstverwaltung", Jura, 2: 121-133.

Schoch, F. (2007), "Verfassungswidrigkeit des bundesgesetzlichen Durchgriffs auf Kommunen", Deutsches Verwaltungsblatt, 5: 261-269.

Schoch, F. (2008), “Neukonzeption der kommunalen Selbstverwaltungsgarantie durch das Bundesverfassungsgericht?”, Deustches Verwaltungsblatt, 15: 937946.

Schoch, F. y Wieland, J. (1995), Finanzierungsverantwortung für gesetzgeberisch veranlaßte kommunale Aufgaben. Baden-Baden: Nomos.

Stern, K. (1977), Das Staatsrecht der Bundesrepublik Deutschland, Vol I. Múnich: CH Beck.

Stüer, B. (2007), "Verwaltungsreform auf Kreisebene - Effektivitätsgewinn nur bei bürgerschaftlichem Engagement", Deutsches Verwaltungsblatt, 20: 1267-1274.

Tettinger, P. (2000), “Artikel 28 GG”, en Mangoldt et. al., dirs., Bonner Grundgesetz Kommentar, Vol 2 (Art. 20-78), 4 a ed. Múnich: Franz Vahlen.

Thieme, W. (2007), "Die Gliederung der deutschen Verwaltung“, en Mann, T. y Püttner, G. (dirs.), Handbuch der kommunalen Wissenchaft und Praxis, Berlín: Springer.

Velasco Caballero, F., dir., (2010), Gobiernos Locales en Estados federales y descentralizados: Alemania, Italia y Reino Unido. Barcelona: Institut d'Estudis Autonòmics. 
Ricard Gracia Retortillo

Von Unruh, G.C. (1972), “Der Kreis - Ursprung, Wesen und Wandlungen”, en AAVV., Der Kreis, Vol. I. Colonia-Berlín: Grote.

Wiese, R. (1972), Garantie der Gemeindeverbandsebene? Frankfurt Main: Athenäum Verlag.

Recibido: 27 de octubre de 2010

Aceptado: 22 de febrero de 2011 